\title{
Manuel Lueiro Rey frente a la censura franquista: los avatares de Manso
}

\author{
Andrea Bresadola \\ Universidad de Macerata
}

Título: Manuel Lueiro Rey frente a la censura franquista: los avatares de Manso.

Resumen: El presente artículo recorre la vida y la producción literaria de Manuel Lueiro Rey. Estudiamos las vicisitudes editoriales que sufrió su obra al enfrentarse con los órganos de la censura franquista. Una represión ahora iluminada a través de los expedientes conservados en el AGA y el examen de la documentación de la época. Reconstruimos la trayectoria de la novela Manso, profundizando en las circunstancias que rodearon a su primera edición (Oviedo, 1967), en virtud de los cortes impuestos y sus motivaciones ideológicas. Hacemos públicos, por primera vez, los informes de los censores, ahondando en la figura y labor historiográfica del militar Gárate Córdoba, primer responsable de supresiones orientadas a mermar la carga conflictiva de una obra antibelicista. Finalmente, ofrecemos los resultados del cotejo entre el mecanografiado entregado por la editorial al departamento censorio, la princeps, y la segunda edición (1968), publicada íntegra en Buenos Aires.

Palabras clave: Manuel Lueiro Rey, Manso, Censura franquista, Narrativa de Posguerra, Novela social.

Fecha de recepción: 7/12/2017.

Fecha de aceptación: 13/12/2017.
Title: Manuel Lueiro Rey against Franco's Censorship: Manso's Vicissitudes.

Abstract: This article explores the life and literary production of Manuel Lueiro Rey, analyzing the editorial vicissitudes of his work beginning with his clash with the Francoist censorship organization. A repression we can document thanks to the files stored at the AGA and contemporaneous documents. In particular, we can re-enact the trajectory of the Manso novel, investigating the circumstances that led to the first edition (Oviedo, 1967) and examining the imposed cuts and the ideological reasons behind those cuts. For the first time, censorship reports are made public, shading light in particular on the figure and the historical work of the serviceman Gárate Córdoba, the first person in charge of the suppressions aiming to reduce the conflicting value of an anti-war work. Lastly, results of the collation between the typescript delivered by the publishing house to the censorship department, the princeps and the second edition (1968), published in its whole form in Buenos Aires, are presented.

Key words: Manuel Lueiro Rey, Manso, Francoist Censorship, Postwar Narrative, Social Novel. 
"Ci dividono solo piccole sfumature ideologiche" En memoria del maestro y "Jefe" Giuseppe Mazzocchi

\section{Manuel Lueiro Rey: Un ESCRITOR ANTICONFORMista ${ }^{\mathrm{I}}$}

Manuel Lueiro Rey (1916-1990) fue periodista, agitador cultural, militante antifranquista y autor de una producción literaria muy variada que abarca poesía y narrativa. Si bien se asomó en español a la república de las letras, a partir de la segunda mitad de los años sesenta empezó a componer también en gallego, y desde entonces fue alternando los dos idiomas. Podemos decir que a este bilingüismo corresponde también un distinto tratamiento de su obra dentro de ambos acervos. En la literatura española, Lueiro no ha gozado de la fama que merece: su nombre resulta casi desconocido y apenas lo menciona la crítica académica. Ha disfrutado de mejor fortuna en su Galicia natal, donde, sobre todo en las últimas décadas, se han ido multiplicando ediciones, estudios y encuentros culturales dedicados a su memoria ${ }^{2}$. Proyectos nacidos con la intención de

1 Quiero agradecer su valiosa ayuda a Adela Lueiro, Ramón Nicolás, José Manuel Ramos y, finalmente, a Chiara.

2 Esto se debe en particular a los esfuerzos de Ramón Nicolás y Xesús Alonso Montero, cuyos estudios y ediciones citaremos a menudo en estas páginas. Sobre los homenajes cfr. Ramón Nicolás, "Introducción", en Manuel Lueiro Rey, $O$ sol na crista do galo, ed. Ramón Nicolás, Vigo, Xerais de Galicia, 2003, pp. 7-152 (pp. 56-59). Ya en enero de 1991, poco más de dos meses después de la muerte de Lueiro, la revista Dorna le dedicaba una sección con recuerdos de literatos y amigos. Modesto Hermida García ("Manuel Lueiro Rey, unha paixón silenciada”, Dorna, 17 (1991), pp. 89-92) subrayaba la indiferencia hacia su obra en España y, paralelamente, un cierto escepticismo en la crítica gallega, debido a su bilingüismo. Si la situación dentro de las letras españolas no ha cambiado, en el sistema literario gallego este recelo se ha mitigado con el tiempo. Además de las iniciativas señaladas por Ramón Nicolás, añadimos que en 2016 (con ocasión del centenario del nacimiento del autor) en Pontevedra (con la colaboración del Concejo y la Diputación Provincial), Pontecaldelas, Poio y otras localidades se celebraron encuentros, actos, exposiciones, coloquios, recitales y la presentación del libro Camiño aberto, 100 anos de Lueiro Rey (1916-2016). De especial importancia son los dos certámenes literarios (en lengua gallega) convocados a su nombre: en 1992 se celebró la primera edición del Premio Novela Corta, organizado por el Concejo de Grove; mientras 
rescatar su labor creativa y, a la vez, su trayectoria civil. Efectivamente, su producción no puede escindirse de su compromiso, ni de las luchas que protagonizó. "Mi obra forma parte de mí mismo"” sintetizaría en distintas circunstancias.

Lueiro cruzó gran parte de la convulsa y densa historia de la España del siglo XX. Era todavía adolescente cuando se proclamó la Segunda República, y tenía tan solo 20 años al estallar la guerra fratricida. Pasó entonces su madurez y gran parte de su vida durante los largos años de la dictadura, aunque llegó a ver también la llamada Transición y el primer decenio de la recobrada democracia. Etapas que no dejó correr en silencio delante de sus ojos: a pesar de vivir apartado de los grandes centros de la cultura y la política nacional, el escritor gallego siempre sintió un incansable afán de cambio social, al que dio voz en formas y maneras distintas. Así, se enfrentó al Régimen con el arma en la que siempre confió, la palabra, a través de artículos, conferencias, mítines y, finalmente, la literatura. Su obra — sin menoscabo de su valor estético — puede leerse como un instrumento más de su oposición e inconformismo ante el status quo. Según un ideal de corte marxista, estaba convencido de que la creación artística podía despertar las conciencias y mantener viva esa memoria histórica que el Nuevo Estado pretendía borrar. La cultura tout court, en suma, entendida como forma de resistencia. Por eso siempre le otorgó un papel destacado y se batió para que volviese al pueblo, puesto que "la cultura no puede ser un monopolio, es decir, no puede ser un privilegio de los ricos [...]; debe ser de todos y para todos, para que el hombre recobre el cauce de la vida normal que le robaron" ${ }^{\text {. }}$

que en 2012 el Concejo de Fornelos de Montes y la Asociación de Vecińos o Cruceiro da Laxe inauguraron el homónimo premio de poesía. Señalamos, finalmente, la interesante página http://manuellueirorey.com/web/, rica en datos biográficos y bibliográficos, noticias, archivos fotográficos y audiovisuales.

3 Diario de Pontevedra, 11/12/1966, p. 14.

4 Discurso pronunciado en la Casa de Galicia de París en 1967, con ocasión de "O Día das letras galegas". Se ha reproducido su intervención en "Alocución del Sr. Lueiro Rey en el acto celebrado en París el día 27 de mayo para conmemorar el "Día das letras galegas”, Nova Galicia: revista de cultura y política, II, 4 Trimestre Segundo (1967), pp. 16-17. 


\section{Perfil biográfico y literario}

Lueiro nació el 9 de abril de 1916 en Fornelos de Montes, municipio en la provincia de Pontevedra; siete años después su familia se trasladó a $\mathrm{O}$ Grove, en la comarca del Salnés.

A principios de los años treinta debió de entrar en las Juventudes Comunistas Unificadas ${ }^{5}$, y cuando tenía tan solo 19 años publicó su primer artículo —en contra de la pena de muerte - en El País de Pontevedra ${ }^{6}$. Durante el fatídico 1936 se alineó con las posiciones del Frente Popular, participando en la campańa política junto al Comité Local de la Izquierda Republicana, en Fornelos, apoyando también la campańa por el estatuto de autonomía gallega, que se iba fraguando. Con el estallido de la guerra y la rápida caída de Galicia en mano de los sublevados, se refugió en los montes, consiguiendo eludir los "paseos" que los falangistas practicaban en contra de cada sospechoso. A medida que la represión se intensificaba, Lueiro entendió que no tenía otro remedio que alistarse en el ejército golpista. Así las cosas, ingresó en 1937 en el Cuerpo de Sanidad. Atravesó varias zonas de Galicia para luego seguir el conflicto en el Frente Norte: Teruel, Quart de Poblet y, finalmente, Asturias, donde contrajo el tifus. Pasaría los últimos meses de la guerra encarcelado por un incidente con un superior. El trágico conflicto — no podía ser de otra manera — le marcó para siempre. La memoria de la guerra, su inutilidad y sufrimiento, serán una preocupación constante, y tendrán reflejo en muchos de sus escritos, a partir de la novela que nos ocupa: $\mathrm{Manso}^{7}$.

5 Ramón Nicolás ("Introducción”, p. 17) dice no haber podido concretar la información. El biógrafo, sin embargo, no duda de que Lueiro se aproximó, antes y después de la Guerra, a las doctrinas comunistas.

6 "La pena de muerte. Su ineficacia" puede leerse en el apéndice del citado volumen O sol na crista do galo (pp. 291-293). Lueiro dedicará su colección de artículos, Crónica de una transición intransigente (1985), también a "Roberto Blanco Torres, Director de El País de Pontevedra, asesinado en 1936, que fue el primero que me publicó un artículo”. En 2016, bajo la supervisión de Nicolás Antonio y prólogo de Xesús Alonso Montero, se dio a la estampa un libro que recoge prosas periodísticas del autor: Novas crónicas dunha transición intransixente (Santiago de Compostela, Laiovento).

7 Trató el tema en numerosos artículos (sobre todo de los años ochenta) y en textos literarios, como el poema "Agonía de un soldado" (La noche espera el alba), los 
Terminada la guerra, volvió a Fornelos, aunque se trasladó pronto a Madrid, donde en 1942 sacaría una plaza como auxiliar de cuerpo técnico del Ministerio de Hacienda. Dos años después pudo regresar a Galicia, tras aprobar una oposición en el mismo ministerio de la Delegación de Pontevedra. Durante esos años reanudó también su actividad periodística, colaborando en diarios y revistas ${ }^{8}$. Asimismo volvió a la militancia activa, tomando contacto con el Partido Comunista en la clandestinidad. En dicho contexto, ya hacia mediados de los Cincuenta, colaboró de forma secreta con Radio España Independiente, la célebre "Pirenaica". Como me ha comunicado Adela Lueiro - hija del autor-, envió cartas sobre la situación española y gallega a un enlace que tenía en Francia,

cuentos "Hundezelle", "Ya había llegado la primavera" (Hundezelle y otras vidas maltratadas), ¿Mais, foi ansî́?" (O Sol na crista do galo), "El niño que tenía un oso de trapo" y "La noche de san Silvestre" (Vicente y el otro). Al respecto cfr. Román Arén, Un río de sangue e tinta. A Guerra Civil Española e o Franquismo na narrativa dos galegos, Boiro, A.C. Barbantia, 2006, pp. 92-93.

8 Destacamos, en primer lugar, sus contribuciones en revistas literarias como Blanco y negro o Ínsula. Además, su firma apareció tanto en periódicos locales (Faro de Vigo, El Pueblo Gallego, Diario Regional de Valladolid, etc.) como en nacionales e internacionales ( $A B C$, Mundo gallego de Buenos Aires etc.). Para más detalles remitimos de nuevo a Ramón Nicolás (“Introducción”, pp. 27-29 y 87-96).

9 La radio, surgida en el seno de la Komintern, funcionó desde el 22 de julio de 1941 hasta el 14 de julio de 1977. Emitió desde Moscú (con un breve paréntesis en Ufa en 1943) hasta enero de 1955, cuando se trasladó a Bucarest. "La Pirenaica" intentó ser la única voz disidente en el éter de la España posbélica, cuyo objetivo fue coordinar la oposición comunista. La bibliografía sobre el tema es numerosa; cfr., entre otros, María Salvador García, "Radio Pirenaica, la otra voz del franquismo", Historia, XVI, 265 (1998), pp. 22-27; Antonio Ortiz Mateos, "La guerrilla y la radio. El papel de Radio España Independiente en el movimiento guerrillero español (1941-1952)", Espacio, tiempo y forma. Serie V, Historia Contemporánea, 25 (2013), pp. 327-340, y, sobre todo, Luis Zaragoza Fernández, Radio pirenaica. La voz de la esperanza antifranquista, Zaragoza, Marcial Pons, 2008, en particular, por lo que se refiere al período de colaboración de Lueiro Rey, el capítulo IV: "Años dorados (1956-1968)". Aquí se precisa (pp. 217-221) el papel de escritores como Alfonso Grosso, Juan García Hortelano o Jesús López Pacheco, quienes aportaron "indudable calidad literaria" a las emisiones, con la ventaja, además, de gozar de "mayor protección frente a la policía, pues la Brigada Político-Social siempre tuvo sus escalas en el ensañamiento durante los interrogatorios, y a un escritor era difícil que le tocaran tanto como a un obrero". 
remitiéndolas desde distintos puntos de Galicia para evitar los controles. Solo en estos casos Lueiro podía expresar su punto de vista sobre lo que le rodeaba, ajeno a toda forma de autocensura, pues recobraba esa libertad de expresión tan ferozmente reprimida en los medios oficiales ${ }^{10}$.

Fue precisamente dentro del asfixiante panorama cultural de la dictadura cuando debutó como literato. Su vocación es un poco tardía: cuando tenía 34 años dio a la luz su opera prima con el seudónimo "Gudea": Nacencia. Cuentos y poemas ${ }^{11}$. Habría que esperar otros nueve para que saliera su segundo libro, esta vez firmado con su propio nombre, el poemario Juncia de amor y vida (1959). En 1967, la publicación de Manso dio comienzo a su obra narrativa propiamente dicha. La novela es un género que cultivaría poco, ya que en su prosa priorizó la forma breve ${ }^{12}$.

En noviembre de 1968 emprendió su primer viaje a Argentina, invitado por la "Unión Hijos del Grove" de Buenos Aires. Repetiría la experiencia cuatro años después. En América del Sur se acercó al dinámico mundo cultural de los refugiados (principalmente del círculo galleguista),

10 El mismo autor escribía en la citada dedicatoria de Crónica de una transición intransigente: "A Ángel Huete, gran periodista [...] cuando me aconsejaba que escribiese "con tiento" para que la censura franquista no se alborotase". Efectivamente, Ramón Nicolás ("Introducción", pp. 89-90) anota cierta actitud "pragmática" de Lueiro, que tuvo que autocensurar a menudo su pensamiento en los escritos periodísticos. Bien es verdad que a partir de los años sesenta empezó a redactar artículos más reivindicativos con declaraciones antibelicistas, en favor de la literatura social o en apoyo a personajes declaradamente marxistas como Bertold Brecht.

11 Para todos los detalles bibliográficos véase Ramón Nicolás, "Introducción". El volumen misceláneo Nacencia salió en 1950 en la Editorial Roel de Vigo. Se trata de un libro tan poco conocido que en los catálogos de la BNE y de la Red Española de Bibliotecas Universitarias (REBIUN) no se especifica el verdadero nombre del autor. Lueiro ya había utilizado este seudónimo en varios escritos periodísticos. "Gudea" hace referencia a un gobernador de Mesopotamia del III milenio a. C.

$12 \mathrm{Su}$ producción prosística comprende la miscelánea de relatos breves Nacencia (1950), las colecciones de cuentos Vicente y el otro (1968), O sol na crista do Galo (1982), Hundezelle y otras vidas maltratadas (1998) y, finalmente, Non debian medrar (1974), que puede definirse como una novela corta, pues roza las 100 páginas (el volumen fue adaptado y traducido al castellano en 1987 por el mismo autor con el título Un río que camina). La muerte le sorprendió cuando tenía preparadas dos nuevas novelas, una en español y otra en gallego: La marea roja y $A$ illa dos corvos mouros. 
trabando profunda amistad con Arturo Cuadrado, Lorenzo Varela y Luis Seoane. La estancia fue "una nueva vida", una huida — aunque efímeradel control del Régimen. Como escribió muchos años después, supuso

sobre todo y por encima de todo, la recuperación (tan solo por un mes, desgraciadamente), de la libertad y de la palabra que la guerra franquista nos había robado. La España viva del exilio allí estaba en Buenos Aires delante de mí ${ }^{13}$.

Según veremos, en Argentina vieron la luz algunos libros censurados o que consideró impublicables en su patria, aunque no sin consecuencias. Además, fue probablemente la influencia de este ambiente lo que le inclinó a escribir en gallego, lengua que en determinadas ocasiones le pareció más adecuada para expresar su identidad e intimidad. En 1971, pues, editaría su primer poemario gallego: Un tempo de sol a sol ${ }^{14}$.

Después del fin del Régimen continuó — ahora sin el condicionante de la censura estatal o autoimpuesta - sus colaboraciones periodísticas y actividades culturales. No abandonó su espíritu crítico, siendo una de las voces disonantes en el clima de pretendida concordia nacional de la que definió como "Transición intransigente". A su juicio, la recobrada democracia se mostraba demasiado temerosa de renegar de la dictadura y de ajustar cuentas con su sangriento pasado ${ }^{15}$. En 1979 se presentó a las

13 Manuel Lueiro Rey, "Marquina, Galicia, Buenos Aires", Faro de Vigo, 14/5/1988, p. 2. Francisco Lores, "Lueiro Rey na Arxentina”, en Manuel Lueiro Rey (1916-1990). A liberdade ferida, coord. Ramón Nicolás, Vigo, Xerais de Galicia, 2013, pp. 9-12, p. 12 vio en la experiencia americana un salto cualitativo tanto desde el punto de vista literario como político. Cfr. también Ramón Nicolás, "Introducción”, pp. 3953; y, del mismo estudioso, "Lorenzo Varela e Manuel Lueiro Rey: crónica dunha amizade", en Manuel Lueiro Rey (1916-1990). A liberdade ferida, pp. 104-120 (pp. 106-109).

14 Acerca de esta obra y, en general, a propósito de su uso del gallego, cfr. Ramón Nicolás, "Introducción", pp. 66-73 y Xesús Alonso Montero, "Sobre Lueiro e sobre a novela Manso", en Manuel Lueiro Rey, Manso, Vigo, Galaxia, 1996, pp. 9-19 (pp. 12-15).

15 Una postura que le costó una cierta desconfianza y el silencio de los medios de comunicación, tanto que Ramón Nicolás (“Introducción”, p. 94) afirma no haber podido encontrar ni reseńas ni notas críticas sobre Crónica de una transición intransigente. 
primeras elecciones municipales democráticas, siendo elegido en $\mathrm{O}$ Grove ya afiliado a las listas del PCE. Ejerció así de Concejal de Cultura desde el 19 de abril de ese año hasta el 20 de mayo de 1983: una experiencia, sin embargo, que le desilusionó.

Continuaría editando, tanto en gallego como en castellano, hasta Vigo en tres paisajes (1990), que cuidó hasta sus últimos días, si bien por desgracia no lo llegó a ver en las librerías.

Lueiro falleció en O Grove el 11 de octubre de 1990. Su funeral fue sin ceremonias religiosas, con el féretro envuelto en una bandera roja con la hoz y el martillo.

\section{REPRESIÓN POLÍTICA Y REPRESIÓN EDITORIAL}

Lueiro tuvo que enfrentarse en distintas circunstancias a la represión estatal. Aunque la dictadura nunca descubrió sus actividades clandestinas, los agentes franquistas vieron con desconfianza su creciente acercamiento a los ambientes comunistas y republicanos. Estuvieron alerta especialmente durante sus estancias en América Latina, preocupados de que fuese una ocasión para una propaganda contraria al Movimiento Nacional. Baste recordar los obstáculos que le pusieron con motivo de su segundo viaje. En primer lugar, las autoridades le secuestraron el pasaporte, obligándole a aplazar la salida. Luego, ya en Buenos Aires, como recuerda Francisco Lores, "personaxes de embaxada española na Arxentina ameazaron con pór unha bomba en Mendoza na sala onde o nos escritor ía dar unha conferencia. Non puxeron unha bomba, mais si bomobiñas fétidas"16. Finalmente, a su regreso hubo de entrar por Portugal, porque en Madrid le esperaba la policía para interrogarle sobre sus actividades y publicaciones en Argentina.

En efecto, fue sobre todo la obra literaria de Lueiro la que se juzgó peligrosa. La simple redacción de poemas (como el que compuso en homenaje a Rafael Alberti o el relativo al golpe de Pinochet) le costó largos interrogatorios y registros domiciliarios ${ }^{17}$. Sobre todo las vicisitudes de $L a$ noche espera el alba atestiguan a las claras la dificultad y los riesgos de es-

16 Francisco Lores, op. cit., p. 11.

17 Cfr. Ramón Nicolás, "Introducción”, pp. 33 y 42. 
cribir versos comprometidos en la España franquista. En 1963, miembros del Estado obligaron al jurado a retirar el Premio de Marina Ourense que le habían otorgado al volumen. Años después, el autor decidió editar el libro en Buenos Aires, concretamente en la editorial "Botella al mar", fundada por Cuadrado y Seoane. Cuando se intentó distribuir el poemario también en la patria, el Tribunal de Orden Público dispuso el secuestro de la edición. A raíz de este episodio, Lueiro fue de nuevo interrogado y se salvó de la detención solo gracias a un lance fortuito ${ }^{18}$.

\subsection{La censura en las obras de Lueiro}

La hostilidad del Régimen hacia la producción literaria de Lueiro se manifestó también a través de otro instrumento omnipresente: la censura previa. Como todo escritor que se dispusiera a publicar un libro en la Espańa franquista, el grovense tuvo que enfrentarse a ese órgano de control. Antes de adentrarnos en la trayectoria editorial de Manso —el caso más paradigmático de violación de la libertad del autor-, veamos los otros disgustos que sufrió nuestro protagonista.

En otras dos ocasiones su obra no pasó indemne por el cedazo de la censura. Dos poemas suyos publicados en volúmenes colectivos (Castelao na voz das poetas y Chile en el corazón) fueron mutilados. Los dos trámites se cursaron en la segunda etapa legislativa de la censura, estando vigente la Ley 14/1966 de Prensa e Imprenta, más conocida como "Ley Fraga"19. Más que la tan proclamada apertura, la nueva ley se redujo a aportar ligeros cambios en el funcionamiento del mecanismo burocrático, manteniendo el organismo censorio (a partir de entonces "Servicio de Orientación Bi-

18 Ibidem, pp. 42-43 y 110-115.

19 Manuel Fraga Iribarne fue Ministro de Información y Turismo desde 1962 hasta 1969. La ley se publicó en el BOE 67, 19-III-1966, pp. 3310-3315. Sobre sus repercusiones en el mundo editorial, cfr. Javier Muñoz Soro, "Vigilar y censurar. La censura editorial tras la ley de prensa e imprenta, 1966-1976", en Tiempo de censura. La represión editorial durante el franquismo, coord. Eduardo Ruiz Bautista, Cenero-Gijón-Asturias, Trea, 2008, pp. 111-142; Gonzalo Dueñas, La Ley de Prensa de Manuel Fraga, [s.l.], Ruedo Ibérico, 1969, especialmente, pp. 58-128, y Francisco Rojas Claros, "Poder, disidencia editorial y cambio cultural en Espańa durante los años 60”, Pasado y memoria. Revista de historia contemporánea, 5 (2006), pp. 59-80. 
bliográfica”) y dejando inalterada la arbitrariedad de sus juicios. La gran novedad era que la editorial podía entregar a depósito el libro sin pasar por la antes obligatoria consulta previa. Sin embargo, esto no impedía que la oficina censoria dispusiese la confiscación de la tirada completa. A menudo, entonces, resultaba aconsejable pasar por la llamada "consulta voluntaria", la otra vía que la ley concedía y que no difería de la precedente normativa sino en detalles apenas terminológicos. En este caso, el editor debía remitir dos copias mecanografiadas al Ministerio de Información y Turismo, y la obra pasaba por las manos de uno o más "lectores" que redactaban los correspondientes informes. La última palabra, sin embargo, correspondía a funcionarios de más alto grado, como el Jefe de Lectorado, el Jefe de la Sección y, finalmente, el vértice de la pirámide, el Director General.

Alonso Montero recapitula así los avatares de la composición de Lueiro "Carta escribo que non ten resposta", incluida en Castelao na voz dos poetas:

un bravo e conmovedor canto a Castelao foi mutilado gravemente [...]. Na censura o lapis do censor chatou na segunda estrofa as palabras [...] a xente chora $\mid$ a morte que ti sabes. [...]. Por orde da Superioridade [...] o espacio das oito palabras aquí en cursiva aparecía con puntos suspensivos ${ }^{20}$.

La documentación conservada en el Archivo General de la Administración (AGA) de Alcalá de Henares nos proporciona la oportunidad de reconstruir el fatigoso camino del libro para llegar a las prensas ${ }^{21}$. En primer lugar, observamos cómo la misma sustitución se da también en otros dos versos de la cuarta estrofa (vv. 15-16), que en el mecanografiado presentado a las oficinas ministeriales se leían así: “Teño a sede dos ferros ousidados | que tecen as rexas carceleiras". El pequeño volumen se había presentado a "consulta voluntaria" el 18 de abril de 1970, bajo el título de Bibliografía de Castelao e Coroa Poética. Se redactaron tres informes: el primer

20 Xesús Alonso Montero, “Sobre Lueiro”, pp. 11-12. Sobre la represión a las obras de Lueiro, cfr. Gustavo Luca de Tena, "O poeta que denunciaba a mentira e encendía os corazóns”, en Manuel Lueiro Rey (1916-1990). A liberdade ferida, pp. 65-68.

21 Sección de Cultura, expediente n. 4078/70, caja 66/5582. Indicaremos siempre el número de expediente y signatura del AGA. 
lector (don 23) declaraba "publicable" la obra en su escueto juicio del 22 de abril. También el segundo, cuatro días después, daba su nibil obstat, aunque insinuando algunos reparos. Este censor es don 8 y la firma parece ser HM: volveremos a encontrarla en más de un informe sobre libros de Lueiro. Por el departamento circularon dos nombres cuyas iniciales, acaso, podrían responder a los nombres de José María Hernández o María V. Hernández. Sin embargo, la identidad del censor se ha resistido a nuestras pesquisas. De momento, entonces, habrá que mencionarle con la sigla HM. Pues bien, tras resumir el contenido del libro, el susodicho escribe ${ }^{22}$ :

El soneto que le dedica Lorenzo Varela —pág 7— puede tener intención política en dos expresiones, pero queda diluida y difusa en la licencia poética. [...] Las fichas 24, 28 y 29, por ejemplo, hacen sospechar por los títulos — no conocemos estos libros- que se trata de obras de contenido político favorable a la España republicana. Ello no obstante, y salvo superior opinión, la nuestra es que puede autorizarse.

El 5 de mayo un tercer lector (don 29) insinúa por vez primera la posible sedición política que asoma en el poema de Lueiro, señalado por el número de la hoja que ocupa en el mecanografiado, la 10:

[...] Algunos de estos poemas aluden a la sempiterna movilidad gallega, una emigración que puede dejar despoblada a Galicia, y en donde solo quedan los "colaboracionistas" y los viejos (10), y que tienen que luchar con su lucha a cuestas, como cada hijo de Dios (6), provocando un sentimiento de rejas, de cadenas, de muerte ( 7 . 10) [subrayado con bolígrafo rojo]. PUEDE AUTORIZARSE. Aunque convendría tal vez introducir algunas tachaduras en los párrafos aludidos. Aunque, por otro lado, dentro del contexto general de loa a un poeta desaparecido pierden su matización político social.

El 15 de mayo la Superioridad emite su resolución: hay que suprimir los cuatro versos de Lueiro indicados, y, además, el v. 4 del poema "Caste-

22 En la transcripción de informes y cartas del archivo se añade la acentuación, muchas veces ausente. El resto se reproduce tal y como figura en los documentos originales, con sus errores, grafías y puntuación, señalando también los subrayados. 
lao", de Lorenzo Varela (hoja 7): "Unha nova Galicia sen cadea”. La editorial tuvo que imprimir el libro poniendo puntos suspensivos en estos lugares. Solo así pudo depositarlo el 24 de abril de 1971, un ańo después de la instancia de solicitud, cambiando además el título por el definitivo Castelao na voz das poetas.

La situación volvería a repetirse en 1974. Una vez más debemos a Alonso Montero la advertencia de que algunos versos del poema de Lueiro "Loitando, sempre loitando", contenido en la antología Chile no corazón, fueron sustituidos por puntos suspensivos ${ }^{23}$. Acudimos al expediente del AGA (exp. n. 7034/74, Sección de Cultura, caja 73/04188) que se abrió para el volumen en homenaje a Pablo Neruda, que contaba, entre otros, con poemas de Jorge Guillén, Vicente Aleixandre, Rafael Alberti, Carlos Barral, Gil de Biedma o Gabriel Celaya. El 17 de junio de 1974 la combativa editorial catalana Edicions 62, cuyo director literario era José María Castellet, presentaba instancia de consulta voluntaria. La obra pasó al lector n. 6, que, gracias a la firma del informe, hemos identificado con Luis Martos, General de División ${ }^{24}$. El militar se expresa en estos términos:

El recopilador [...] ha reunido los versos malos y peores que se han escrito sobre la muerte de Neruda [...]. Algunos, se refieren a Allende y a la guerrita civil de Chile, naturalmente favorables a Allende. Pero sin ser en general demasiado agresivos. Hemos tachado solamente un verso en la pág. 165 porque cita por su nombre a Pinochet, Jefe de Estado reconocido por España al que no se puede admitir insultos. Y otro en las págs 207-208 por excesivamente revolucionario. Se considera por tanto AUTORIZABLE CON TACHADURAS.

Se entregó entonces a otro lector, don 4, el coronel de aviación y miembro del servicio de espionaje Fernando Fernández-Monzón, quien el 25 de junio propone, como réplica a Martos, la prohibición de la obra:

23 La voz de Galicia, 2/10/1998, reproducido en Xesús Alonso Montero, Beatus qui legit. Artigos periodísticos (1998-1999), Santiago de Compostela, Servicio de Publicacións da Universidade de Santiago de Compostela, 2000, p. 40

24 Así lo define Fernando Larraz, Letricidio español. Censura y novela durante el franquismo, Somonte-Cenero-Gijón, Trea, 2014. p. 96: “atrabiliario, rústico, cerril y dogmático. Fue el lector más prolífico en el primer lustro de la década de 1970”. 
[...] todos los poemas aquí recogidos están totalmente politizados en el sentido de unir a la misma figura a Neruda y Allende y la muerte del poeta es tachada de asesinato perpetrado por el actual gobierno chileno. En este sentido la mayoría de las obras seleccionadas son verdaderos panfletos revolucionarios de calro [sic] matiz marxista, plagados de insultos a los ejércitos mantenedores del orden y sin que falten los rebuscados paralelismos del Septiembre chileno del 73 con el Abril español del 39, ni de los "mártires inmolados por el franquismo" del campo intelectual con la muerte de Neruda. Es una obra claramente tendenciosa y panfletaria, que bajo la noble excusa de exaltar la figura de un poeta insigne esconde un interés bastardo de propaganda clandestina marxista con los más soeces insultos a las instituciones del actual y reconocido oficialmente, gobierno de Chile. Se considera que su publicación debe de ser DENEGADA.

El 23 de abril la Superioridad confirmaría la prohibición. El 14 de octubre Castellet presentó solicitud de reposición con una larga y acalorada carta en la que, entre otros argumentos, alega que "rechazar este libro es rechazar en bloque a la literatura española de hoy y esto es algo que no creemos que entre ni en la política del Ministerio, ni en la mentalidad de ningún hombre que valore la cultura”. La defensa del crítico catalán sirvió para levantar la prohibición pero no para impedir una serie de cortes. La Oficina contactó con la editorial y emitió la decisión final de "silencio administrativo". Era una opción que consentía al Ministerio descargar toda la responsabilidad de la publicación sobre la editorial, que asumía la posibilidad de una denuncia o bien del secuestro de la tirada en cualquier momento. No hay documentación que dé fe de los pasajes que la Administración ordenó suprimir. Una nota manuscrita en la citada misiva de Castellet informa de que fueron señaladas de manera oficiosa a la editorial: "Comunicadas verbalmente algunas supresiones. Se presentará directamente el depósito". Al cotejar el mecanografiado presentado con la edición definitiva nos damos cuenta de que desaparecen composiciones enteras (como la de Xavier Bru de Sala) y algunos versos. Entre estos cuatro (vv. 2, 19, 20 y 21) de la traducción española del poema de Lueiro, aunque no figuraba entre los indicados por el primer lector: "Yo ya tenía veinte años | eumplidos en el treinta y seis [...] Ayer nosotros y hoy tú. Nosotros con Hitter y Mussolini... |Tú con la C.I.A. y con la I.T.T...”. El 
original gallego mecanografiado ya presentaba, en cambio, puntos suspensivos (Alonso Montero reproduce los versos en su artículo). Posiblemente esta omisión se deba a una previa autocensura de la editorial.

Las demás obras de Lueiro que transitaron por el departamento estatal no sufrieron podas. Sin embargo, los informes emitidos nos ayudan a entender el clima de sospecha en que se movía el autor y la incultura y prepotencia de los lectores. En el AGA (Sección de Cultura) se guardan los expedientes de otras seis obras de Lueiro que vieron la luz entre 1959 y 1982, así como de otros dos volúmenes colectivos que incluyen un relato (Sexto certamen internacional de cuentos) y versos (Antonio Machado na nosa voz) salidos de su pluma. Se reproducen los títulos en orden cronológico, indicando número de expediente, signatura y fechas de apertura y resolución del trámite, desde el envío de la solicitud hasta la aceptación del depósito.

- Juncia de amory vida: exp. n. 2606/59, caja 21/12428; (29/5/195915/7/1959);

- Sexto certamen internacional de cuentos: exp. n. 1049/68, caja 21/18732; (6/2/1968-7/2/1968);

- Antonio Machado na nosa voz: exp. n. 1201/67, caja 21/17926; (26/12/1966-14/2/1967);

- Non debian medrar: exp. n. 9076/74, caja 73/04313; (28/8/197411/9/1974);

- Tempo de sol a sol. $2^{\circ}$ ed.: exp. n. 1103/75, caja 73/04617; (21/1/1975-30/1/1975);

- Del corazon de mi pueblo: exp. n. 14400/77, caja 73/06412; (19/12/1977-21/12/1977);

- Escolma ferida: exp. n. 282/78, caja 73/06440; (2/1/197811/1/1978);

- Conversaciones con mi hijo: exp. n. 3830/82, caja 73/07882; $(4 / 6 / 1982-7 / 6 / 1982)$.

El intervalo desde el primero hasta los últimos expedientes certifica la progresiva pérdida de fuerza y capacidad represora del organismo, aunque sus funcionarios se resistieran a aceptar los cambios políticos y sociales que vivió el País durante los años setenta y ochenta.

En el catálogo del AGA no consta el expediente de censura del debut de Lueiro, Nacencia. Cuentos y poemas, aunque cualquier libro con desti- 
no comercial debía pasar la censura. Es posible que el sobre que lo contenía esté mal catalogado (quizás debido al uso del seudónimo Gudea) o se haya extraviado ${ }^{25}$. Así, es Juncia de amor y vida el primer volumen de Lueiro que desembocó en el entonces llamado "Servicio de Inspección de Libros". Es el único título de nuestro autor que se edita estando vigente la ley de Prensa de Serrano Súner, que databa de 1938 e instituía la obligatoriedad de la consulta previa para cualquier publicación no periódica. El 29 de mayo de 1959 el mismo Lueiro mandó la instancia de impresión, indicando una tirada de solo 250 copias. El poemario fue autorizado el 18 de junio y depositado el 15 de julio. Sin embargo, el lector (el abogado Ángel Sobejano, como deducimos de su firma) se atrevió a lanzar un despectivo juicio: "Una serie de renglones cortos que el optimista autor titula poesías. Carecen como tales de fondo, de forma y de todo valor literario. No obstante ateniéndonos al cuestionario PUEDE PUBLICARSE”.

El resto de los expedientes se abrieron durante la época de la "Ley Fraga”. Se presentó directamente a depósito —y fue aceptado sin trabas - el Sexto certamen internacional de cuentos (que contenía "Vicente y el otro").

El Círculo de las Artes de Lugo optó acertadamente por el depósito también en el caso de Antonio Machado na nosa voz, librito "impreso a multicopista” de homenaje al poeta republicano. Aquí aparecía el primer poema escrito en lengua gallega por Lueiro, "Agonia da lambranza”, traducido del espańol por el propio autor con la ayuda del poeta y amigo Antonio Tovar. Aunque el depósito se aceptó al día siguiente, se redactaron dos informes. Ambos lectores subrayan que con la antigua ley habrían tachado algunos versos "para evitar la posible retorcida intención de los autores que tejen la Corona o desgranan las canciones”. Sin embargo, ni a los lectores ni al Director de la Sección les pareció razón suficiente

25 No podemos descartar del todo que el libro solo circulase de manera clandestina y por canales de venta "no oficiales"; en ese caso la editorial pudo evitar la presentación de la solicitud de autorización estatal. La ausencia del número de depósito en la edición, así como la atribución de los derechos "de propiedad del autor" (como se lee en la página legal) podrían apoyar esta hipótesis. En el catálogo del archivo tampoco se encuentra la documentación relativa al librito Sonetos a la ciudad de Vigo, impreso en 1960 por Talleres Hijos de Eladio Portela. En este caso, los datos legales en el colofón del libro ("Depósito Legal: P.O.-42-60 Núm. Registro: P.O.7-60") nos empujan a pensar que el trámite de la autorización se cursó, pero que su expediente no está localizable. 
para prohibir los pasajes con "alusiones políticas". Concluye el segundo lector, don 13: "como la obra viene «en depósito", no se advierte manera de evitar jurídicamente su difusión, por no evidenciarse de manera clara la intención de atentar a los principios del Movimiento Nacional”. El volumen, por lo tanto, pudo editarse. Los dos lectores, de todas formas, no aluden al poema de Lueiro. Alonso Montero ha examinado el expediente de censura en el ensayo que precede a su edición facsimilar de 2009, reproduciendo además los informes en el apéndice $\mathrm{II}^{26}$. Remitimos a esas páginas para obtener un cuadro completo del asunto: solo añadimos que, de nuevo, fue el lector HM quien escribió el primer informe.

HM firmaría asimismo los de las dos siguientes obras presentadas por Lueiro. Se admitió sin obstáculos el depósito de Non debian medrar catorce días después de la instancia. Una vez explicado el argumento, HM sentencia: "Nada, en absoluto, que objetar. Puede autorizarse".

Sí mostró más de un reparo, en cambio, a propósito de la segunda edición de Tempo de sol a sol. Poemas de neno galego (la primera había salido en Buenos Aires en 1971, Edición Centro de Betanzos). En su largo informe, en el que no ahorra pullas, condena el retrato que hace Lueiro de los niños gallegos: la miseria pintada en el poemario es falsa, y proyecta una imagen nociva del Nuevo Estado que no se corresponde con las mejoras sociales que se han efectuado en Galicia. Otro "defecto" es la presencia de alusiones a la Guerra Civil y sus secuelas. No falta, en esto, un tema tabú, que volveremos a encontrar en Manso, como es la presencia de los moros al lado de los nacionales.

El niño gallego ante la realidad que la vida le ofrece desde su nacimiento, constituye la temática monocorde y quejumbrosa de estos poemas. El nińo situado en la realidad sociológica de una Galicia pobre y desmedrada, como si tal fuera la generalidad indiscriminada. [...]. Y tal estampa no es cierta, por cuanto ha mejorado el nivel económico de la Región y, desde luego, todos los niños gallegos tienen hoy escuelas en edificios buenos simplemente aceptables. Nos

26 Xesús Alonso Montero "Un achegamento a Antonio Machado na nosa voz (Lugo, 1966) trinta e tres anos despois", en Antonio Machado na nosa voz, ed. facs., Vigo, Edicions Xerais de Galicia, 2009, pp. 11-48. El estudioso aporta también un dato sobre la tirada, que fue de tan solo 300 ejemplares (p. 40). 
parece objetable — por la insinuación que hace de los moros traídos acá, aunque no concreta cuándo- el poema "Neno sin Escuela", de la pág $\underline{28}$, por la encubierta alusión a la guerra civil. Igualmente objetaríamos y pediríamos la supresión de algún adjetivo en el poema de la pág. $\underline{30}$ [subrayados con bolígrafo azul]. Pero como ya está editado y no se somete a consulta voluntaria, creemos que las objeciones encontradas no ofrezcan entidad suficiente para rechace judicial.

La Superioridad, finalmente, decreta que "Evidentemente las frases subrayadas a lápiz negro a las págs. 28, 30 y la rima blasfematoria de la pág. 63 impiden que el libro sea aceptado libremente por lo que procede que pase por silencio". Por carecer de motivos de peso para su prohibición, la obra pudo circular, aunque otra vez bajo la fórmula del "silencio administrativo". Los subrayados a los que se refiere el funcionario - como comprobamos en uno de los dos ejemplares guardados junto con el expediente- son: "Africa, onde están os mouros, | os mesmos que truxeron | pra vir matalos homes | nas nosas corredoiras" ("Neno sin escola", vv. 12-14, p. 28); una palabra del poema "O berrar do neno": "Berrade forte, sempre, | hastra faguer da terra, | a terra nosa, ceibe" (v. 17, p. 30); y, finalmente, otra del "Poema de espranza" (v. 10, p. 63): "Non hai mal que cen anos dure, | nin cristo que os resista". Versos que se salvaron justo por no presentarse a consulta voluntaria.

Los tres últimos trámites se emprendieron después de la muerte de Franco, cuando ya estaba en marcha el proceso de la "Transición”. En 1977, el Real Decreto-Ley 23/1977 oficializaba la disolución del Movimiento Nacional y del Ministerio de Información y Turismo, mientras que al año siguiente la Constitución derogaba, de hecho, la ley 14/1966. Sin embargo, el aparato de censura siguió funcionando - o por lo menos creía hacerlo - incluso cuando se había disuelto el Régimen que lo había creado, y faltaba ya el respaldo legal, político y judicial para llevar a cabo sus resoluciones ${ }^{27}$.

El 19 de diciembre de 1977 se depositan los ejemplares de Del corazón de mi pueblo, volumen en homenaje a Alberti que contiene un poema de Lueiro en lengua espańola: “Te abrazaré en Granada”. Aunque el de-

27 Cfr. Francisco Rojas Claros, "La represión cultural durante la Transición: los últimos libros prohibidos", Represura, 3 (2007). 
pósito es aceptado tras solo dos días, se redacta un informe. No se hace referencia a Lueiro, pero las palabras del lector (con firma ininteligible y al que tampoco se atribuye número) demuestran que siguen vigentes los criterios de antaño:

Es casi motivo constante el cantar el exilio de Alberti y otras veces su lucha desde el 36, pero en los vascos se acentúa también su lucha por la libertad de su propio país al que se considera aherrojado y perseguido (pgs, 82, 106 y 165 [sic]. Con todo creemos que lo señalado no constituye base suficiente para una impugnación. El pie de imprenta es correcto.

Pocos días después, el 2 de enero de 1978, se presenta a depósito Escolma ferida que igualmente dio pie a un informe por parte de un lector ( $\sin$ número):

Conjunto de poesías, la mayoría de ellas de lamento y queja contra la opresión sufrida no solo por el pueblo gallegom [sic] eternamente emigrantem $[s i c]$ sino por la falta de libertad de España entonces encadenada (pg. 20), queja contra el Julio de 1936 (pg. 21), elogio al Che Guevara (pg. 71) y acusaciones contra el régimen de Pinochet, lamentándose de las violencias en Chile. Con todo, lo señalado no parece tener entidad suficiente para una impugnación, y el pie de imprenta es correcto.

El último trámite (Conversaciones con mi hijo) se cursa en el siguiente decenio. La solicitud, con fecha 4 de junio 1982, se dirige ahora al recién nacido Ministerio de Cultura y a la "Dirección General de Promoción del libro y de la cinematografía. Promoción editorial”. Empero, todavía se hace referencia a: "las previsiones de la Ley de Prensa e Imprenta de 18 de marzo de 1966". Se indica también un lector (n. 10), pero ya no hay informes. Solo se marca una $X$ en "No procede adoptar las previsiones del artículo 64 de la Ley de Prensa e Imprenta" y "Requisitos formales completos". El siete de junio de 1982 se autoriza el depósito. Solo a partir de esta fecha tan tardía las obras de Lueiro quedarán libres de control. 


\section{MANSO}

Manso relata la historia de un caballo que vive los trágicos años de la Guerra Civil y la primera posguerra. Nacido entre los "matorrales espesos de la alta montaña de Lugo", es arrebatado a su madre con apenas dos meses por unos mozos de la aldea gallega de Freaza. El potrillo es domado y muestra enseguida su actitud pacífica ayudando en las faenas de los labradores, "arrastrando el arado" o "recorriendo las ferias con la mercancía de la zoquería” de Basilio. Un día se insinúan confusos rumores sobre la rebelión de los militares contra el gobierno republicano. Las consecuencias del estallido de la guerra no tardan en manifestarse y trastornan la vida de la aldea: los jóvenes tienen que alistarse en el ejército y los soldados, en nombre de la Patria, requisan también a Manso. Lo llevan al cuartel de Vigo y luego participa en la campańa del Norte, acompañado por Bendańa, un joven de Freaza. Entre la nieve de la batalla de Teruel, el animal es herido por una metralla y "sale corriendo al galope, desbocado", atravesando el frente. Al acabar la guerra cae en manos de Ramírez, dueño sin escrúpulos de una fábrica de tejas, quien lo fuerza a trabajar duramente hasta que, agotado por el barro de la hoya, muere en las orillas del $\operatorname{mar}^{28}$.

El lector, sin embargo, no lee los acontecimientos según la disposición lineal que acabamos de trazar, pues no hay coincidencia entre fábula y tiempo del relato. En las páginas iniciales tropezamos, pues, con la figura de Ramírez, empeńado en comprar el caballo de un gitano en 1941. El primer capítulo continúa con el relato de la fatigosa jornada de los traba-

28 Silvia Carballido Reboredo, Novela en pé de guerra. A Guerra Civil vista polos novelistas galegos en castelán, Sada, Ediciós do Castro, 2001, p. 121, indica en la novela "Número 13" de Wenceslao Fernández Flórez un antecedente narrativo cuyo hilo conductor es un caballo en el contexto de la Guerra Civil. Sin embargo, no hay otros elementos en común. La novela de Fernández Flórez (editada en 1941) relata la búsqueda de un famoso caballo ganador del derby por parte de un detective británico en la zona republicana. Además de la trama — completamente distinta—, la postura ideológica y política de Fernández Flórez se encuentra en las antípodas de la de Lueiro, siendo su obra un ataque satírico contra los "rojos" que roza lo panfletario. Como escribió Julio Rodríguez Puértolas, Historia de la literatura fascista española, Madrid, Akal, 2008, vol. I, p. 514: “todos los tópicos y clichés habituales del fascismo español acerca de sus enemigos aparecen aquî". 
jadores de su tejería. Solo a partir del segundo arranca la larga analepsis que narra la vida de Manso en orden cronológico. La lucha fratricida ocupa la parte central del libro, con un doble enfoque: por un lado, el del caballo, parte del microcosmos de las tropas sublevadas (con la oposición entre los altos mandos — arrogantes y violentos - y los jóvenes soldados inocentes); por otro, el punto de vista de los aldeanos. Solo en el último capítulo se reanuda brevemente el hilo inicial: la acción se sitúa dos meses después, y culmina en el amargo desenlace. Lueiro explota esta técnica de interrumpir la secuencia temporal a lo largo de toda la novela, cuando afloran recuerdos, paréntesis o nuevas analepsis que dan cuenta del pasado de los personajes que Manso se cruza en su camino.

\subsection{Lecturas criticas}

La novela puede encasillarse dentro del "realismo social", corriente narrativa que —en definición de Sobejano - apuntaba "hacia el vivir de la colectividad española en estados y conflictos que revelan la presencia de una crisis y la urgencia de una solución" ${ }^{29}$. Una literatura testimonial, entonces, que pretendía desvelar a través de una mirada objetiva y crítica la cara más ruin y desalińada de la Espańa franquista, oculta por el falso triunfalismo de los medios oficiales. En Manso la búsqueda de una estética realista se advierte en situaciones, personajes y lenguaje, del todo verosímiles, situados dentro de coordenadas cronotópicas concretas y "verdaderas", como las de los años treinta y cuarenta en una aldea gallega. El mismo autor ha defendido en más de una ocasión la voluntad de crear una ficción que se alimentase de la vida misma, única manera de representar con eficacia y contundencia la situación social y rescatar la memoria reprimida de la historia de España:

Pongo la imaginación al servicio de la realidad. Me gusta soñar y pisar la tierra. No tener ciegos los ojos ni entontecida el alma. Nutrirme de lo que yo vivo y de lo que viven los demás. Porque si el hombre está hecho de sueños han de ser sueños amasados

29 Gonzalo Sobejano, "Reflexiones sobre La familia de Pascual Duarte", Papeles de Son Armadans, XLVIII (1968), pp. 19-58 (pp. 35-36). 
con voces y con tierra. Adoptar otra postura lo juzgo una inmoralidad $^{30}$.

En nuestra novela dicha realidad se cifra en la dura lucha para sobrevivir en una localidad olvidada por el poder y saqueada por la guerra, como aclara Lueiro desde las páginas del mismo periódico:

Es la narración sencilla de unos personajes que viven circunstancias trágicas, demostrando la inmensa resistencia que tiene el hombre ante las adversidades. [...] [Pretendo] hacer llegar al lector el abandono total en que se encuentran las aldeas de cualquier país. [...] Muy poca gente se ocupa de ellas hasta que llega la guerra. Cuando la guerra llega, como allí hay hombres y cosas que sirven para la guerra, entonces se acuerdan de las aldeas. Segundo, [pretendo] acusar el miserable estado social de un sector humano, donde el hombre malvive, como si fuese un bicho extraño.

Al escritor no le interesa la significación político-ideológica de la Guerra, ni quiere explicar sus causas o profundizar en las posiciones de los dos bandos (los republicanos, además, apenas asoman por la narración). La guerra es el mal absoluto, más allá de las circunstancias. Podríamos afirmar, entonces, que se trata de una novela antibélica, más que de la exaltación de los que se opusieron al alzamiento.

Dentro de la literatura española la obra es prácticamente desconocida, y son muy pocos los estudios que van más allá de su simple mención ${ }^{31}$. Podría haber distintos motivos para explicar esta penuria. En primer lugar, es posible que la crítica haya considerado a Lueiro preferentemente como poeta, y, a tenor de su limitada producción novelística, solo raramente se le encasillara dentro de la nómina de los narradores. También

$30 A B C, 7 / 9 / 1967$, p. 21 . No es difícil ver en esta novela la trasposición de episodios autobiográficos, sacados del vivo recuerdo del autor. Por ejemplo, el hecho de que se relate la campańa del Norte desde el punto de vista de las Fuerzas de Sanidad. Hallamos también situaciones más puntuales que rememoran la vida de Lueiro, como un personaje que huye a los montes nada más comenzar la guerra.

31 En publicaciones generales sobre la narrativa de la posguerra ni siquiera se le nombra. Así, por ejemplo, en La novela española contemporánea (1939-1967) de Eugenio G. de Nora o en la Historia de la novela social española (1942-1975) de Sanz Villanueva. 
su condición de autor bilingüe ha contribuido a soterrar todavía más su nombre en la literatura española. Además, como se aclarará, la novela casi no circuló, fruto de los contenciosos con el Ministerio y del hecho de que las únicas dos ediciones (1967 y 1968) se agotaron enseguida. A estos problemas editoriales y censorios quizá haya que añadir que Lueiro siempre permaneció "fuera de las ferias y vanidades de la promoción" y no pareció interesado en demasía por la difusión de sus escritos ${ }^{32}$. En los años cincuenta y sesenta, por varias razones (geográficas, de formación y generacionales), el autor gallego también anduvo al margen de los círculos intelectuales de los grandes centros urbanos, animados por jóvenes que buscaban una salida al estancamiento de la cultura del Régimen ${ }^{33}$. Dicho “aislamiento" probablemente limitó aún más el conocimiento de Manso. Un olvido extendido aun después del final de la dictadura.

Así las cosas, contamos casi solo con algunas reseńas que aparecieron en las proximidades de la primera edición. Una de las primeras salió en el diario $A B C$ el 29 de junio de $1967^{34}$. Su responsable vaciaba la novela de cualquier carga conflictiva, transformándola en una tragedia melodramática:

32 Xesús Alonso Montero, "A modo de prólogo", en Manuel Lueiro Rey, Hundezelle y otras vidas maltratadas, Barcelona, Ronsel, 1998, pp. 9-11 (p. 10).

33 "Durante anos e anos Lueiro foi un escritor solitario, en solitario. Residía no Grove, unha illa desvencellada de toda relación litearia, e traballaba, 'pro pane lucrando", na Delegación de Facenda de Pontevedra, un ermo burocrático" (Xesús Alonso Montero, "Unhas palabras sobre o ecritor Manuel Lueiro Rei", Dorna, 17 (1991), pp. 83-84). Madrid y Barcelona, en cambio, fueron terreno fértil para encuentros de intelectuales, novelistas, poetas y editores que debatían sobre cómo la literatura —y más en concreto la novela social— podía llegar a constituirse en medio de lucha política. Basta pensar en las tertulias del café Pelayo o en las reuniones de autores como Ignacio Aldecoa, Rafael Sánchez Ferlosio, Jesús Fernández Santos y Carmen Martín Gaite en la capital; o en la llamada Escuela de Barcelona, que se convirtió en núcleo de la industria editorial anti-Régimen. Gracias a Carlos Barral, muchos autores de la nueva literatura comprometida pudieron imprimir sus obras y difundirlas incluso en el exterior. El aislamiento de Lueiro también se dio en el sistema literario gallego, dominado en aquel entonces por el grupo Galaxia, que propugnaba un frente exclusivamente cultural y literario como resistencia al franquismo. Una visión que Lueiro no podía compartir.

$34 A B C, 29 / 6 / 1967$, p. 45. 
Es la conmovedora historia de un caballo que, como su nombre indica, es un dechado de mansedumbre y sacrificio. Pero el caballo es quien con su andadura lenta e indiferente nos hace atravesar un mundo y recorrer un camino lleno de sorpresas y de dramáticas enseñanzas. Arrancado de su aldea gallega, anda de aquí para allá siguiendo los acontecimientos de nuestra guerra hasta morir, puro montón de huesos y mataduras, entre el barro viscoso de un tejar.

De más interés son las sucesivas críticas que vieron la luz en revistas literarias, como la madrileńa Punta Europa, que alaba el texto por mor de su preocupación realista y su "autenticidad". Sin embargo, fiel a un canon de juicio "objetivista”, el reseñador a veces juzga la prosa de Lueiro "en exceso floreada”35. Meses después, José Domingo, desde las páginas de Ínsula —una de las publicaciones más heterodoxas y plurales de aquel tiempo- resaltaba, en cambio, esa combinación de realismo y lirismo que, como se decía, el mismo autor consideraba la esencia de su producción. Después de subrayar la originalidad de la novela (aunque advertía "hechuras indudables de obra primeriza”), el crítico alaba la lograda búsqueda de un comprometido realismo descriptivo: "las escenas bélicas se nos describen tal como acaecen en la realidad: vulgares, grises, despojadas de toda esta faramalla que acaba por convertirlas en hechos heroicos"; mientras que "cuando la obra tiene por escenario la vida en las aldeas galaicas, sus páginas se iluminan con una fragante y natural poesía, la del proprio paisaje" 36 .

En fechas más recientes, ciñéndonos al ámbito gallego, se ha analizado la novela desde una óptica más amplia, enmarcándola dentro de los

35 "Lueiro Rey", Punta Europa, XII, 127 (1967), p. 88. Para otras reseñas de la época, cfr. Ramón Nicolás, "Introducción”, pp. 101-102. También Xesús Alonso Montero, "La obra de Manuel Lueiro Rey. A modo de introducción", en Manuel Lueiro Rey, Vicente y el otro, Buenos Aires, Oberón, 1968, p. 9, destacó algún exceso lírico en Manso: "esta prosa tan lograda, y lograda con facilidad, no siempre sirve con precisión los objetivos del escritor. Páginas hay en que la dramaticidad de las cosas y de las situaciones queda diluida en el verbo trabajado del narrador. Es riesgo en el que incurren los escritores que, como Lueiro, ven en el idioma una fascinación y una tentación constante. Se impone en tales casos saber bien lo que se persigue con la palabra para que ésta no vista de "poesía" una realidad que hay que desnudar".

36 José Domingo, “Manuel Lueiro Rey, Manso", Insula, 255 (1968), p. 7. 
cauces de todo el corpus del autor. Así, Ramón Nicolás lee Manso como novela paradigmática de los rasgos habituales del Lueiro poeta y narrador: “a reflexión sobre a opresión política e social, o sufrimento e os límites de resistencia do ser humano; a carencia de liberdades e a inxustiza social" 37. Xesús Alonso Montero ya había avanzado una exégesis alegórica en esta dirección: "Na pluma de Lueiro a historia do cabalo non é unha historia inocente. Ademais de ser un recurso técnico para tecer, arrededor del, historias e vidas humanas, Manso protagoniza unha alegoría, unha parábola, ó seu modo, do pobo español" 38 . En efecto, el caballo parece encarnar los valores del pueblo español y, especialmente, de los aldeanos, con los que comparte inocencia, humanismo, sumisión y, a la postre, el trágico destino de la guerra. Un paralelismo categórico fortalece tal asociación: la madre de Manso aparece "muerta al fondo del barranco", desesperada por la pérdida de su potrillo. De igual modo, a Isabel se la encuentra "en el fondo del agua", tras recibir la noticia de la muerte de su hijo. Antecedentes del binomio "caballo-pueblo" víctima de la violencia franquista, y quizá posibles fuentes de inspiración para Lueiro, podrían rastrearse en dos obras que el autor admiraba y citó en repetidas circunstancias. La primera es pictórica: el caballo del Guernica de Picasso, a menudo glosado como trágica representación del martirizado pueblo español ${ }^{39}$. Por el otro, el potro que se asoma al principio y al final de Réquiem por un campesino español de Ramón J. Sender, libro que, como veremos, es una piedra de toque de Manso también para un censor del Ministerio. Aunque en la novela del aragonés el caballo asume un papel menor respecto a Manso, cobra cierta relevancia dramática, evidenciada en los momentos clave de la narración para avivar el recuerdo de Paco en Mosén Millán e interrumpir la hipócrita celebración de la misa. El potro es el espíritu del campesino y, como explica Carrasquer, consigue "resucitar simbólicamente al pueblo español matado a palos, a puyazos, a balazos" ${ }^{40}$.

37 Ramón Nicolás, "Introducción”, pp. 99-100.

38 Xesús Alonso Montero, "Sobre Lueiro", pp. 15-16.

39 Lueiro dio forma narrativa al célebre cuadro en el cuento "El niño que tenía un oso de trapo", publicado en Vicente y el otro (pp. 71-74).

40 Francisco Carrasquer, "Introducción", en Ramón J. Sender, Réquiem por un campesino español, Barcelona, Destino, 1998, pp. V-LXXXI (pp. LXVI-LXVIII). 
Basilio Losada, por último, vio en Manso una metáfora del soldado ${ }^{41}$. Como los jóvenes obligados a alistarse, el caballo es arrastrado al frente y regresa sin voluntad de vivir (con "una tristeza humana impresionante" en los ojos). Su mismo nombre y "la virtud de ser pacífico" que le caracteriza fortalecen dicha analogía, así como su oposición a los mandos militares que creen, en cambio, que "la guerra es necesaria".

\subsection{La génesis de la novela}

En una entrevista del 11/12/1966, Lueiro recordaba así la gestación de Manso: "Fue creciendo poco a poco. Empezó como un cuento breve. Luego novela corta. Después comprendí que daba para más y se convirtió en la reciente novela" 42 . El germen fue, entonces, el cuento "Manso, caballo de carne y hueso", que solo se publicó en 1998 en la antología póstuma Hundezelle y otras vidas maltratadas ${ }^{43}$. El largo relato (43 páginas) ya contenía argumento, protagonistas y estructura de la novela, coincidiendo, además, en numerosos segmentos textuales. Su autor, pues, solo retocó en muchas ocasiones lo ya escrito, limándolo, perfeccionándolo y ańadiendo pinceladas. Sobre todo incorporó nuevas descripciones y diálogos y alargó la trama con algún episodio (como la requisa del caballo y la detención y sucesiva muerte de José, el maestro de aire machadiano), redactando ex novo los capítulos VI, VII, XI y XII.

Tales etapas de composición y progresiva ampliación terminaron por lo menos en octubre de 1966, cuando Manso optó al premio "Ciudad de Oviedo" ${ }^{4}$. Luego fue presentado a la Administración estatal el año sucesivo. Antes de que el libro viera la luz, el texto sufrió cambios ajenos a la voluntad del autor, a resultas de la censura. En 1968, Lueiro editaría en Buenos Aires la segunda edición, ya íntegra, para la cual —según se

41 Basilio Losada, "Lueiro e a claridade", en Manuel Lueiro Rey (1916-1990). A liberdade ferida, pp. 61-62 (p. 61).

42 Diario de Pontevedra, 11/12/1966, p. 14.

43 Manuel Lueiro Rey, Hundezelle, pp. 161-203.

44 Herminio Barreiro recuerda la lectura del manuscrito de la novela en casa del autor, aunque no especifica cuándo ("Siempre me acompañará, sempre”, en Manuel Lueiro Rey. A liberdade ferida, pp. 33-34). 
lee en la solapa - se basó la traducción gallega, la única realizada de la novela ${ }^{45}$.

El cuadro de las distintas redacciones de Manso se dispone de la siguiente manera ${ }^{46}$ :

M: mecanografiado presentado al Servicio de Orientación Bibliográfica, enero de 1967;

E1: primera edición; Richard Grandío, Oviedo, junio de 1967;

E2: segunda edición; Oberón, Buenos Aires, octubre de 1968;

$G$ : traducción en gallego; Vigo, Galaxia, 1996.

A estos documentos hay que añadir por lo menos otro, el primer eslabón de la génesis de la obra:

$O$ : mecanografiado entregado al "Premio Novela Ciudad de Oviedo", octubre de 1966 .

Desgraciadamente, no tengo constancia de la supervivencia de este mecanografiado "original" que el autor envió al jurado, o bien de otro manuscrito previo a $M$. Por eso, en lo que se refiere a sus variantes textuales, solo me limitaré a formular hipótesis.

\subsection{El premio "Novela Ciudad de Oviedo"}

En junio de 1966 se anunciaba la convocatoria de la V edición del Premio ovetense, certamen fundado por el librero-editor Richard Grandío y promovido y patrocinado por el Ateneo y el Ayuntamiento de la ca-

45 Aunque salió póstumo, el libro cumple un deseo expresado por el novelista (cfr. Alonso Montero, "Sobre Lueiro", p. 18). Sobre la traducción cfr., del mismo estudioso, "Manso, de Lueiro, en galego", La Voz de Galicia, 28/11/1996, p. 9, y Ramón Nicolás, "Manso, a presencia de Lueiro Rey", en Ramón Nicolás, Papeis de literatura. Dez anos de revisión crítica, Vigo, Xerais de Galicia, 2001, pp. 85-87.

46 Por comodidad, a partir de ahora emplearemos las siglas. No incluimos en este listado "Manso, caballo de carne y hueso" por tratarse de otra obra. Con nuestro estudio, pues, pretendemos reconstruir la evolución de un texto ya fijado, es decir, la novela. 
pital asturiana ${ }^{47}$. La revista La estafeta literaria, entre otras, difundía el reglamento:

Podrán optar a este premio todos los escritores de lengua espańola, presentando un original inédito. Los originales estarán mecanografiados a doble espacio, en papel blanco, tamaño folio u holandesa. Se presentarán por triplicado. La extensión habrá de ser superior a los 200 folios. Deberán ser remitidos antes del día 15 de octubre de 1966 al Ateneo de Oviedo [...]. El fallo se efectuará el 7 de diciembre del año en curso. [...] La cuantía en metálico del premio es de 100.000 pesetas, más el 15 por 100 de la venta de la segunda y sucesivas ediciones, en concepto de derechos de autor. La novela será editada por Richard Grandío, en exclusiva ${ }^{48}$.

Precisamente el 7 de diciembre, el jurado, reunido en el Hotel Principal de Oviedo, declaró como ganadora la novela de Lueiro. En el Diario de Pontevedra de la mañana siguiente leemos:

La obra vencedora obtuvo cinco votos contra dos, respecto de la finalista Semanas perdida con vosotras de Manuel C. Cueto, de Madrid. Ambas novelas [...] fueron las seleccionadas en la VI votación, tras haber sido eliminadas diez más [...]. El Jurado del premio estaba formado por los escritores don Alejandro Núnez Alonso, don José Caso González, don Ángel María de Lera y don Alfonso Vallejo; el periodista Rubén Suárez, el primer teniente de alcalde don Anselmo López, y el presidente del Ateneo de Oviedo, don Luis María Fernández ${ }^{49}$.

47 En las anteriores ediciones resultaron ganadoras las siguientes novelas: Caza mayor de Jorge Ferrer-Vidal (1961), Sexta galería de Martín Vigil (1962), Los niños numerados de Juan Farias (1964) y Unos rosales en China de Antonio Fraguas Saavedra (1965).

48 La estafeta literaria, 346 junio (1966), p. 38.

49 Diario de Pontevedra, 8/12/1967, p. 10. En el Pueblo Gallego del 18 del mismo mes (p. 17) se informaba del homenaje que los colegas le dedicaron al autor tanto para el premio ovetense como para la victoria en el I Concurso Regional de Cuentos "Café real", obtenido pocos días después: "En un céntrico restaurante de esta capital los funcionarios de esta Delegación de Hacienda ofrecieron un almuerzo a su compañero don Manuel Lueiro Rey, para festejar sus recientes éxitos literarios [...]. 
Poco más de un mes después del veredicto, Grandío emprendió los trámites legales para editar la novela.

\section{La Censura de Manso}

El expediente relativo a la publicación de Manso (AGA, Sección de Cultura, exp. n. 747/67, caja 21/17888) nos permite evaluar la envergadura de los cambios impuestos, sus causas y responsables. El papel de la censura estatal fue tan relevante que, con amarga ironía, Alonso Montero llega a afirmar que fue "coautora [sic] do texto da primeira edición da novela" ${ }^{50}$. Antes de penetrar en sus engranajes hay que detenerse en otro tipo de reparo al que tenían que enfrentarse los escritores. Me refiero a la autocensura, condicionamiento menos visible y tangible que los bolígrafos de la oficina del Ministerio, pero que sin duda fue cómplice de la alteración de la literatura española de esas décadas. Abellán, en uno de sus fundamentales estudios, la define como:

las medidas previsoras que, consciente o inconscientemente, un escritor adopta con el propósito de eludir la eventual reacción o repulsa que su texto pueda provocar en todos o algunos de los grupos o cuerpos del Estado facultados para imponerle supresiones o modificaciones con su consentimiento o sin él ${ }^{51}$.

Para el mismo Alonso Montero, la novela —incluso en su versión íntegra- no reproduce lo que Lueiro quería y hubiera sido capaz de escribir:

Nun réxime político tan censorio o escitor autocensúrase, non pouco, sempre. [...] Manso é a obra máis feita e lograda de Manuel Lueiro, unha obra onde non sempre se realiza plenamente, porque o excelente narrador que Lueiro levaba dentro tivo que elaborar un relato sobre a Guerra Civil nunhas coordenadas, as da Censura —e as da

Se pronunciaron brindis en los que pusieron de manifiesto la labor de Lueiro Rey, el que agradeció el agasajo que se le tributaba".

50 Xesús Alonso Montero, "Sobre Lueiro", p. 16.

51 Manuel L. Abellán, "Censura y autocensura en la producción literaria española”, Nuevo Hispanismo, 1 (1982), pp. 169-180 (p. 169). 
autocensura, por tanto- que, ás veces, cortaban o alento e, sempre, moderaban a ambición ${ }^{52}$.

Efectivamente, Lueiro sabía que su obra tenía que ser aprobada por el departamento censorio, si bien a estas alturas todavía no había experimentado sus opresivas decisiones. Es imposible precisar el alcance de tan severa coacción. Sin embargo, no podemos descartar que también Manso naciera condicionada en este sentido, y por ello que Lueiro, de manera más o menos consciente, tuviese que controlar su prosa para sortear una segura denegación.

Como dijimos, en 1966 había entrado en vigor la "Ley Fraga", que permitía elegir entre el depósito directo o la eufemísticamente llamada “consulta voluntaria”. Según se desprende de las palabras del autor en una entrevista al Faro de Vigo ${ }^{53}$, parece que al principio la editorial pensó en la primera opción, pero luego se vio obligada a presentar la obra a consulta: “todo empezó en los primeros días de enero último. La Dirección General ordenó la suspensión de la edición de "Manso» que estaba en marcha; pidió que se le mandase el original a Madrid”. Así, el 21 de enero de 1967 Richard Grandío envía la solicitud de autorización, adjuntando dos copias de la novela $(M)$. En la carta se precisa que fue "galardonada con el premio Ciudad de Oviedo". Aunque no se trataba de un certamen literario tan conocido y mediático como, por ejemplo, el Nadal o el Planeta, una obra ganadora podía ejercer cierta presión sobre el Servicio de Orientación Bibliográfica, temeroso de un escándalo en caso de denegación ${ }^{54}$.

El Jefe de Negociado de Registro firma el 28 de enero la instancia. Se abre así el expediente 747/67.

52 Xesús Alonso Montero, "Sobre Lueiro", pp. 18-19.

53 Faro de Vigo, 24/3/1967, p. 12.

54 Fernando Larraz, op. cit., pp. 126-128 y 185-187, trae a colación algunos episodios en este sentido. Entre ellos la novela de un jurado que votó por Manso en el certamen ovetense, Las últimas banderas de Ángel María de Lera. La obra fue premio Planeta en 1967. En esta tesitura, el censor, a pesar de haber redactado un informe muy crítico, apoyó la aprobación explicitando su criterio pragmático: "dado el carácter de premio público concedido a ésta y en evitación de la propaganda que se le pudiera hacer con una denegación". 


\subsection{El mecanografiado}

Pieza fundamental en la tarea de reconstrucción de la trayectoria de la novela es $M$, documento que, según mis datos, no se ha mencionado nunca en los estudios sobre Manso.

Encuadernado en papel acartonado amarillo, consta de 232 hojas (21,5 x 29,5cm) escritas solo a una cara, con numeración de 1 a 228 añadida con bolígrafo azul en la parte superior derecha. Entre la hoja 118 y la 119 hay una que lleva el número 118 bis, mientras que otra está sin numerar entre la 147 y la 148. En la portada se lee, trazado a bolígrafo azul "Novela", "Manso, y, además, el número de expediente y el sello "Archivo" del Ministerio. En la primera hoja aparecen en el centro el nombre de autor y el título, y, en la parte inferior: "Presenta: Manuel Lueiro Rey Roffignac -16- $4^{\circ}$ Pontevedra".

Hay diversas intervenciones hechas por los censores con lápiz y bolígrafos rojos y azules: se trata tanto de palabras subrayadas o tachadas, como de trazos, corchetes y llaves en los márgenes del texto. En cinco ocasiones (cfr. $\$ 4.4$ ) los lectores añaden también algunas palabras en sustitución de las tachadas (y en la h. 194 se escribe "vale" para aprobar el cambio). Otras veces, como demuestran la tinta y las diferentes manos, las correcciones manuscritas (hechas con bolígrafo rojo, azul o verde) se deben a quien mecanografió el texto, un encargado de la editorial o incluso el mismo autor. En estos casos se enmiendan palabras mal escritas o se sanan pequeños olvidos, casi siempre una sola palabra. De la misma manera registramos (unas 160 veces) palabras o líneas enteras tachadas con la máquina de escribir y las relativas correcciones mecanografiadas atribuibles a quien pasó a limpio la novela. Finalmente, la puntuación y la acentuación son a menudo aproximativas.

No podemos precisar si $M$ reproduce a plana y renglón el mismo texto que triunfó en el certamen. Lo cierto es que la novela del mecanografiado transmite considerables variantes con respecto a la edición bonaerense (E2). Llama la atención, sobre todo, la falta de muchos pasajes en $M$. Ausencias, por supuesto, que no pueden atribuirse (por lo menos de manera directa) a la intervención de las oficinas estatales, puesto que $M$ es anterior al paso por la censura. La edición argentina, en suma, no es una mera reproducción de $M$ con la incorporación de las partes tachadas en 
E1. Se añaden, en cambio, más de otras 450 líneas en total (que corresponden a unas 15 páginas), relativas en ciertos casos a segmentos que miden hasta una página entera seguida ${ }^{55}$. En la práctica totalidad atañen a la guerra: descripciones del duro ambiente del cuartel, poblado de chivatos y mandos violentos, corruptos y ávidos; fragmentos que desmitifican el conflicto, describen la represión de los sublevados o la intervención de alemanes y moros.

No podemos afirmar a ciencia cierta quién, cómo y en qué momento se produjeron estas variantes en ausencia de $O$ y de declaraciones iluminadoras por parte de los protagonistas del complicado iter de la novela. Una hipótesis es que la editorial podó el texto antes de entregarlo a los censores, evidentemente considerando que no se pudiese publicar tal y como lo escribió Lueiro. Uno de los efectos de la "Ley Fraga” fue, en efecto, el incremento del mecanismo de autocensura:

esta nueva modalidad censoria obligó a los editores a vigilar — pero, sobre todo, a expurgar - mucho más que antes los manuscritos, ya que, en el caso nada hipotético de que alguna personalidad o institución del régimen considerara que lo publicado había infringido de algún modo la ley, el editor era subsidiariamente cómplice del delito cometido ${ }^{56}$.

La tipología de las partes ausentes hace pensar, lógicamente, en este tipo de censura previa, puesto que, como veremos, no difieren en contenido y tipología de los cortes que luego hará el Servicio de Orientación Bibliográfica. Si esta conjetura es correcta, la primera edición sería el resultado de una doble censura realizada en momentos sucesivos y por dos entidades distintas.

Sin embargo, no podemos descartar que para el certamen el autor presentara el mismo texto de $M$, y que Lueiro redactara las nuevas partes con vista a la versión argentina, sabiendo que estaba libre, por fin, de las cen-

55 También el ejemplo $C$ que refiere Alonso Montero ("Sobre Lueiro", p. 17) en su cotejo de las dos ediciones. Un párrafo que, sin embargo, no fue excluido de E1 por el Servicio.

56 Manuel L. Abellán, Censura y creación literaria en España (1939-1976), Barcelona, Península, 1980, p. 118. 
suras. En este caso habría añadido, en un segundo momento, detalles y páginas que recrudecen sus acusaciones hacia los sublevados y aumentan la carga antibelicista.

Sea como fuere, $M$ es una novela censurada: autocensura del autor (que esperó a que la novela saliera al exterior para retocarla) o de la editorial, que mandó a las oficinas ministeriales un texto ya mutilado.

\subsection{Los informes}

El 30 de enero se asigna $M$ a un lector. Es HM, el censor que, como vimos, durante los años siguientes redactaría informes sobre otras obras de Lueiro (todas ellas en gallego) y que siempre está identificado con el número 8. En su veredicto del 1 de febrero traza las líneas de la trama, y a continuación, mecanografiado, ańade:

Hay alusiones al comportamiento de un Sargento con los soldados — pág. 138 —; a algún exceso en la zona nacional — pág. 140, 189-; al clima propio de la contienda civil -192, 221—. [subrayados a bolígrafo azul].

En definitiva, es una novela inserta en el clima de la Guerra civil española, vista desde el lado nacional, reflejando los temores y las inquietudes de las gentes a través de los aldeanos de Sotolongo y de un zoquero que, por haber estado en América, tenía opiniones propias sobre la guerra, sobre toda guerra, causante de desgracias, perturbaciones y males.

Salvo mejor criterio de la Superioridad, la creemos autorizable [subrayado a máquina].

HM considera entonces que la novela puede autorizarse. Indica cinco pasajes "sospechosos" que, sin embargo, admite por insertarse en el "clima de la Guerra civil espańola”. En las páginas señaladas (que marca también con trazos laterales rojos en $M$ ) se hallan, respectivamente: los abusos del sargento a un soldado de La Coruña (h. 138); el recuerdo de un asesinato cometido por los nacionales (h. 140), dos diálogos de Basilio, en los que afirma que los militares habrían fusilado a su primo (h. 189) y los acusa de haber matado al maestro (h. 192) y, finalmente, las 
descripciones de los soldados arrancados de sus aldeas para ir a la guerra (hh. 220-221).

Sin embargo, las altas esferas del Departamento no consideraron suficiente este juicio; de modo que el 8 de febrero la obra pasa al lector don 23 , experto en cuestiones castrenses, que termina su informe apenas dos días después. Contesta afirmativamente a tres de las preguntas del formulario estándar: ¿Ataca al Régimen y a sus instituciones? y ¿A las personas que colaboran o han colaborado con el Régimen? y, finalmente, a la última, que anticipa su denegación: ¿Los pasajes censurables califican el contenido total de la obra?

Escribe, además, un largo y detallado informe mecanografiado:

Novela de ambiente bélico-militar, con tema central en la biografía del caballo de una aldea gallega [subrayado a máquina]. Los primeros capítulos describen con morosidad bucólica la juventud del caballo de un aldeano que no tiene otra riqueza. Con la guerra del 36, un pelotón de sanidad se lo requisa amenazando al dueño. En la aldea no entienden de política, "cosa que no debiera solucionarse a tiros”. La Guardia Civil —nunca vista allí por los chicos— se lleva al buen maestro, al que busca, y se teme por su vida. El hijo de otro labriego está en el servicio militar e irá a la guerra que su padre maldice, sin saber qué querrán los militares sublevados, de lo que solo se sigue mal para los soldados arrastrados al matadero (frase del final).

El caballo "Manso" va a la guerra en la sección del teneiente [sic] Lópz [sic], antiguo sargento, bebedor, cobarde, ambicioso, inhumano, un malvado. Junto a él no hay otra figura militar que la de los soldados, que van a la fuertza [sic], tristes, miedosos, serios, callados, quejosos. Las poblaciones gallegas, Coruña, incluso, con gentes huidizas asustadas, solitarias, sin atreverse a hablar ni reunirse. El Alzamiento ha sido un pronunciamiento de militares rebeldes con algunos falangistas unidos a ellos. Un personaje, ha sufrido prisión por facilitar la evasión a la otra zona a un jefe socialista al que hubieran fusilado. A sus hermanas les han cortado el pelo y dado a beber aceite de ricino. Bombardean los aviadores alemanes. En Navarra solo hay alemanes e italianos. El teniente ama la guerra y elogia sus bienes.

El informe continúa en otro folio, escrito acaso más tarde y sin releer el previo, ya que empieza repitiendo casi a la letra el final de la primera parte: 
El Alzamiento aparece como un pronunciamiento militar “ ¿Qué querrán los militares ahora!". Se nombra a "los militares rebeldes" que se sublevan apoyados por algún grupo falangista. Un personaje ha sufrido prisión por ayudar a evadirse a un jefe socialista que hubiera sido fusilado, del que se toman represalias cortando el pelo y haciendo beber ricino a sus dos hermanas. En Navarra solo descansan de la campańa del Norte italianos y alemanes y bombardean los pilotos alemanes. El teniente ama la guerra y elogia sus ventajas. Los soldados desean morir para librarse de sufrimientos. Se filosofa sobre la guerra y la muerte y los deberes militares y la ambición militar y la picardía para lograr ascensos. La pintura del teniente con su asistente es demoledora y antimilitar, como todo el texto, aun siendo de Sanidad, lleva fusta, como dato de hinchazón despótica, y con ella ha cruzado la cara a algún soldado. La amenaza a su asistente ha costado un mes de arresto al sargento "Mariposa", el único militar que hay junto al teniente en la novela, cuyo apodo le viene de su afeminamiento y contoneo de caderas.

Se insiste en los tópicos vulgares y sensibleros de las novelas remarquianas, los pacíficos hijos arrancados de sus madres, en lo mejor de la vida, cuando más gozan, para morir sin saber porqué. $\mathrm{O}$ solo porque lo quieren los militares.

Las dos figuras centrales, junto al caballo protagonista, son el teniente López y el asistente Bendańa, cuyo amigo José muere en la batalla de Teruel y cuya madre es hallada en el río, al que corrió como loca, descubriéndose la causa en la carta del Cuartel General del Cuerpo de Ejército de Galicia (firmada sin duda por el general Aranda, aunque no se pone la firma) dándole cuenta de la muerte heroica de su hijo, por la Patria; carta que en el contexto suena a ironía amarga. El mulo muere a consecuencia de una herida en Teruel.

La novela es típica contra el Alzamiento, el Régimen, la Guerra de Liberación, el Ejército y la profesión militar. Su semejante más próximo, en otro terreno, es "Réquiem por un campesino español". Escrita con cierto estilo, realista, no perdona ninguna palabra del argot tabernario, y de las tintas negras, exageradas hasta la caricatura, de lo que fue Ejército de Franco y Zona Nacional. Aun suprimiento [sic] todas las páginas acotadas, quedaría el tono negativo de la guerra, el ejército y los mandos, sin justificación posible, como en la más injusta de las guerras. 
A renglón seguido, propone la que Larraz ha definido como "una de las soluciones más insólitas que hemos encontrado y, al mismo tiempo, más intrusivas en la libertad del escritor" ${ }^{\prime 5}$ :

La solución hipotética y muy problemática, para publicarla, estaría más fácilmente en cambiar de bando el relato para tratar de que suceda en el Ejército Rojo, al que cuadra mejor cada uno de los trazos de personajes y ambientes. Tal vez fuese muy fácil, solo con poner en Asturias el origen, el pueblecito de Sotolongo de Lugo.

Preferible acaso a llevarlo a Cuba u otro país hispanoamericano [añadido de puño y letra en el margen izquierdo, probablemente por otro funcionario].

Acaso con variar veinte líneas o treinta se consiguiese. De otra forma la publicación parece rigurosamente inaceptable, pues está entre las peores novelas rojas publicadas fuera de Espańa por Sender, Max Aub y demás exiliados.

Sea o no prescriptivo, es muy lógico el informe previo del Estado Mayor Central del Ejército, salvo en la solución apuntada en el párrafo anterior, pues toda la obra, en conjunto y en detalle parece afectada por el Código de Justicia Militar y además por los principios del Movimiento.

En resumen. Salvo la problemática posibilidad de ambientar la novela en zona roja:

NO DEBE AUTORIZARSE.

En el margen superior, finalmente, apunta 45 páginas que contienen fragmentos que hay que expurgar, y que hallan correspondencia en corchetes y signos laterales a bolígrafo rojo en $M$. Son, en total, unas 300 líneas que, siguiendo la maquetación del mecanografiado, corresponderían a alrededor de diez hojas. Su sacrificio, sin embargo, no bastaría para salvar la obra.

La firma al final del informe se lee con claridad. Podemos así sacar del anonimato al lector n. 23 e identificarlo sin género de duda con José María Gárate Córdoba.

57 Fernando Larraz, op. cit., p. 137. 


\subsection{El censor José Maria Gárate Córdoba}

Nos parece oportuno detenernos en la figura del lector, ya que resultó clave en el proceso de censura de Manso. Sus palabras son emblemáticas de cómo el sector más ideológico del Servicio (y, por ende, del franquismo) recibía una novela antibelicista, y nos hace comprender por qué se decidió a tomar medidas. Gárate Córdoba no es un simple censor de escasa cultura que se limita a cumplir con las órdenes como último eslabón del mecanismo. Se trata, en cambio, de un fervoroso defensor de los principios del Movimiento y representante de los aparatos que lo sustentaban. Teniente Coronel del Servicio Histórico Militar, conjugó la carrera en el ejército con una prolífica actividad como historiador, antólogo, periodista y memorialista, siendo autor de una producción casi del todo relacionada con la historia militar y, especialmente, con la Guerra Civil ${ }^{58}$. En sus textos siempre se mantuvo fiel y propagó los dictámenes del Movimiento, puesto que, en palabras de Reig Tapia, "a pesar de pretender limitarse al campo puramente militar, [...] no puede impedir una serie de comentarios fuertemente condicionados por su ideología justificativa del régimen franquista" ${ }^{2}$.

Nacido en 1918, Gárate era muy joven cuando estalló el golpe. Ingresó en el Ejército Nacional en Burgos, alcanzando pronto el grado de alférez provisional. Estuvo luego en el frente de Madrid y participó en las campañas del Norte y Cataluña. Sus recuerdos sobre la contienda quedan reflejados en su exitoso Mil días de fuego, un himno a la lucha por la

58 Ocupó importantes cargos en el mundo de la historiografía y la docencia castrense durante y después del Régimen de Franco. Por ejemplo, fue el Primer Secretario General de la Comisión Española de Historia Militar, Asesor Histórico en la redacción de las Reales Ordenanzas del Ejército y Jefe de Redacción de revistas y de la sección de Ciencia Militar en diversas enciclopedias. Perteneció también al Centro Superior de Estudios de Defensa (CESEDEN). Su obra es vasta; ya en 1977, en la solapa de su La poesía del descubrimiento, se lee: "Ha publicado 16 libros y más de dos mil artículos y charlas radiofónicas, habiendo obtenido 10 premios literarios”. Entre sus monografías citaremos Las fuerzas armadas (1965), La guerra de las dos Españas: Breviario histórico de la guerra del 36 (1976), Alféreces provisionales: la improvisación de oficiales en la Guerra del 36 (1976), Los intelectuales y la milicia (1983).

59 Alberto Reig Tapia, Ideología e historia. (Sobre la represión franquista y la guerra civil), Madrid, Akal, 1986. p 67. 
patria contra los enemigos comunistas ${ }^{60}$. Según observa Alcalde Ángel, el militar reprodujo — como en otras de sus obras — los "mitos" franquistas sobre el enfrentamiento fratricida: exalta su valor épico, el sentimiento de camaradería entre los jóvenes soldados, el papel formativo del conflicto, y hasta llega a considerar "bonita" o "apacible" alguna operación bélica ${ }^{61}$. En el prólogo revela también las motivaciones que le empujaron a escribir su memorial. Quería restablecer la verdad histórica contrastando la abundancia de narrativa escrita por los "enemigos irreconciliables de la Espańa de Franco". No es difícil imaginar que entre estos incluiría también a Lueiro:

Se produjo una saturación de obras escritas por los vencidos, algunos muy significados en su bando, con un fondo de resentimiento en su apariencia inocua, donde lo ideológico y el partidismo ambiental priva sobre las acciones bélicas [...]. [Mi interlocutor] me decía que es urgente contrarrestar el aluvión de la literatura bélica demoledora y faltan quienes escriban sus propias experiencias $^{62}$.

A la luz de su concepto de la historia y de la importancia política que atribuía a las publicaciones sobre la Guerra, no sorprende que fuese con-

60 El libro salió en 1972 gracias al editor falangista Luis de Caralt. Por supuesto, el volumen pasó sin dificultades por el Servicio de Orientación Bibliográfica (AGA, Sección de Cultura, exp. n. 4035/72, caja 73/1804). La editorial decidió presentarlo a consulta voluntaria, seguramente no por el temor a una denegación, sino como signo de lealtad al Ministerio. El lector fue el general Luis Martos, el mismo que propuso las tachaduras en Chile en el corazón. En este caso llegó a definir el libro como "Perfecto desde todos los puntos de vista. [...] Es totalmente AUTORIZABLE". Su informe se transforma casi en una corrección de pruebas, indicando erratas "que habría que señalar a la Editorial".

61 Ángel Alcalde, Los excombatientes franquistas. La cultura de guerra del fascismo español y la Delegación Nacional de Excombatientes (1936-1965), Zaragoza, Prensas de la Universidad de Zaragoza, 2014, pp. 67 y 107-108.

62 José María Gárate Córdoba, Mil días de fuego. Memorias documentadas de la guerra del treinta y seis, Barcelona, Luis de Caralt, 1972, pp. VI-VII. Pocas páginas después (p. X) declaraba explícitamente su postura: "Imparcial no lo soy ni lo deseo, pues que elegí mi parte y mi partido, me basta ser veraz que es lo que importa”. 
tratado por el Servicio de Orientación Bibliográfica ${ }^{63}$. En diferentes expedientes le hallamos, pues, como "segundo censor" para juzgar novelas de contexto bélico y con presuntos ultrajes a militares. En sus juicios Gárate demostró gran intransigencia, traducida a menudo en propuestas de denegación. Padeció su guillotina un libro de Ramón J. Sender, al que, como expresaba en el informe de Manso, considera autor de "las peores novelas rojas publicadas fuera de España”, junto a Max Aub ${ }^{64}$. En enero de 1967 —coincidiendo precisamente con Manso-Gárate estimó impublicable el tercer volumen de Crónica del alba:

La obra es característica de su autor, anarquista personal que no se somete a disciplina alguna [...]. Ante todo es ofensa para el militar, llegando a suponer que todos son ladrones y ofende a sus viudas como libidinosas en general, se burla del honor militar. Expone la traición con naturalidad prácticamente aprobatoria. Dice - Yo no despreciaba a España, pero tampoco la quería. Presenta como frecuente el fusilamiento de soldados en África. Da por deshonrosa la vida militar. Bromea a propósito del funeral de Calvo Sotelo y

63 Para entender su vinculación con el aparato, baste pensar que su Espíritu y milicia salió en Publicaciones Españolas, imprenta del Ministerio de Información y Turismo. La enorme tirada ascendió a diez mil ejemplares. Hemos acudido también al expediente de censura que se abrió cuando el volumen fue presentado a consulta voluntaria. Es inútil decir que fue aprobado sin reparos. Más aún: el lector don 36 destacaba en su informe sus cualidades como "Obra documentada y sencilla, con enfoque original” (AGA, Sección de Cultura, exp. n. 5690/67, caja 21/18274).

64 Era este un pensamiento común entre los funcionarios del Servicio de Orientación Bibliográfica. Como explica Larraz, "Sender, Barea y Aub [...] sufrieron la censura con especial rigor: se los tenía por intelectuales radicales, agresivos, resentidos y recalcitrantes, y, por tanto, imposibles para la vigilancia censoria”; el Réquiem fue prohibido en la patria hasta 1974 y el nombre de Sender "había estado proscrito y ausente de todas las historias literarias" (Fernando Larraz, op. cit., pp. 287 y 294-300). A las relaciones de Sender y Aub con la censura el mismo estudioso ha dedicado un capítulo de su El monopolio de la palabra. El exilio intelectual en la España franquista, Madrid, Biblioteca Nueva, 2009, pp. 281-297. Sobre los avatares de Max Aub cfr. también Javier Lluch-Prats "Un manuscrito del taller de Max Aub”, Olivar. Revista de literatura y cultura españolas, III, 3 (2002), pp. 117-144, y Francisca Montiel Rayo, "Max Aub ante la censura franquista. El azaroso proceso de publicación de La Calle de Valverde", El Correo de Euclides. Anuario científico de la Fundación Max Aub, 5 (2010), pp. 60-71. 
nivela la represión y ensańamiento en zona nacional y roja y explica el Alzamiento como defensa de privilegios ${ }^{65}$.

Tono y contenido no difieren del informe que emitió acerca de la obra de Lueiro. En todos los casos, Gárate lee las novelas equiparándolas a ensayos de corte histórico, sin reparar en que, aunque "realistas", son obras de ficción. Así, en Manso no acepta los retratos que ofrece el narrador de algunos soldados, o las palabras de Basilio, aunque se trate de personajes inventados por el autor. Su preocupación hacia la que considera "realidad histórica” llega a tal punto que alega que el firmante de la carta que le comunica a Isabel la muerte de su hijo es Antonio Aranda, general que estuvo al mando del Cuerpo de Ejército de Galicia, pero que nunca se menciona en el texto. El hecho de que con sus memorias - repetimosGárate quisiera "contrarrestar" obras de literatura confirma una vez más que el censor confunde las fronteras entre realidad y ficción. Señalamos también que parecen escritas de su puño y letra unas correcciones insertadas en $M$ (pero que no pasaron a $E 1$ ) que revelan su obstinación por la precisión y la "verdad" en la terminología castrense. Sustituía, pues, "desmontar el fusil" por "descolgar el fusil" (p. 93), "Desmontan los fusiles" por "Descuelgan los fusiles" (p. 102) e "insignia de Caballería” por "emblema de Caballería" (p. 147).

Si juzga Manso solo por los hechos reales narrados y la ideología que desprende, ¿por qué desde este limitado punto de mira estima la novela tan peligrosa?

En primer lugar, el militar no puede tolerar la pintura negativa del ejército y de la guerra, de cualquier guerra, que en palabras de Lueiro aparece despojada de cada significación mítica. Justo en 1967, Gárate daba a la imprenta Espíritu y milicia, un estudio sobre el pensamiento militar a través de cantares, crónicas y documentos de la Edad Media. Aun tratándose

65 Apud Fernando Larraz, op. cit., pp. 295-297, que añade que "la novela apareció con tachaduras numerosísimas que, en muchos casos, eran relevantes". El estudioso reproduce también otros informes de Gárate, como el de El miedo y la esperanza de Alfonso Martínez Garrido, presentada a consulta en 1965. El militar escribió otro duro informe: "demagogia y derrotismo diluidos en reflexiones sobre la vida y la muerte, el miedo y la esperanza, el odio militar-bélico, la relatividad de los ideales. Positivista su tono, y sin espiritualidad alguna" (ibidem, pp. 133-134). El volumen se editó remendado en 21 páginas. 
de un ensayo histórico, el autor dejaba bien patente su mentalidad y su teoría sobre el papel de los militares en el seno de un país. Concluía el libro, pues, celebrando la llegada de "una democracia militar bien entendida, donde la autoridad y competencia del jefe es la mejor garantía de la libertad, la disciplina y la victoria" ${ }^{66}$. Este pasaje atestigua claramente cómo la glorificación del ejército y las justas campañas bélicas (en nombre de Dios o de la patria) revestían para él una importancia que iba más allá de épocas y naciones. Desde esta perspectiva hay que leer la desdeñosa referencia a Remarque en el informe de Manso. Un nombre que Gárate citará a menudo, aludiendo con toda probabilidad a Sin novedad en el frente $^{67}$. La novela del escritor alemán es el paradigma de esa narrativa que ensalza los aborrecibles valores pacifistas, y por ello condenable, aunque no tenga nada que ver con la contienda española. Para él es un texto que echa por tierra la necesidad de la guerra y sus valores.

Evidentemente, Gárate tampoco puede consentir que se describa como "la más injusta de las guerras" la que él llama "Guerra de Liberación”. El lector manifiesta su desprecio por esta postura y por quien la pronuncia: "en la aldea no entienden de política". En el informe se detiene también en cuestiones más puntuales sobre la Guerra del 36, asunto sobre el que no admite matizaciones. Cualquier lectura opuesta a la oficial es tendenciosa y censurable hasta en la terminología. Así, repite en dos ocasiones que se trata de un "Alzamiento" y que no puede reducirse a una sublevación de militares a la que se han unido "algunos" falangistas. Una tesis que intentó desmontar también en sus ensayos, sosteniendo, por un lado, la teoría de la conspiración comunista, y, por otro, negando que todos los generales apoyaran el golpe ${ }^{68}$. Otra cuestión que considera importante

66 José María Gárate Córdoba, Espíritu y milicia en la España medieval, Madrid, Publicaciones Españolas, 1967, pp. 355-356.

67 Palabras similares se leen, por ejemplo, en el prólogo de Mil días de fuego (op. cit., p. VII): "Decidí escribir unos relatos bélicos que, sin el sensacionalismo remarquiano [...]: presentasen el intenso clima moral de los jóvenes voluntarios y forzosos [...] que pronto sentirían la responsabilidad de mandar más de cien hombres hacia la vida o la muerte".

68 Como en Mil días de fuego, op. cit., pp. 11 y 19: "A raíz de las elecciones se intensificó la actividad de la UME, pues estaba ya clara la inminente revolución roja, y se empezó a preparar el Alzamiento"; "había ya decisión conjunta de acabar con la revolución marxista, inminente también". En obras como La guerra de las dos Españas. Breviario 
es la de moderar la intervención de las fuerzas italianas y alemanas en el conflicto. Un tema al que volvió a menudo, y que fue común en la historiografía franquista (amén de hallar reflejo en la censura) ${ }^{69}$. Se pretendía de esta manera reotorgar protagonismo al Ejército Nacional y privar a los vencidos del papel de víctimas de las potencias extranjeras.

La voluntad de defender tal representación de la guerra como hazaña se revela también en la propuesta de supresión de detalles aparentemente inocentes, que luego fueron salvados por la superioridad. Transcribimos solo algunas de las innumerables tachaduras que obedecen a este propósito: "le hicieron pasar un mes entero sin salir del cuartel" (p. 204) ${ }^{70}$ refiriéndose a la punición del teniente, o los relatos de la dureza del conflicto: "En las caras de los soldados se reffeja el eansancio, y todos ellos levantan las piernas con esfuerzo, cediendo terreno. Pero el sargento insiste, ame= nazando con un eastigo doble" (p. 145); "Es la desgracia del soldado. pasar hambre e y limpiar el plato con pan” (p. 203). Gárate llegaría a borrar también las quejas de Bendaña al recordar asqueado "el castrón" y las "vacas tísicas" que tuvo que comerse en San Adrián (p. 213).

histórico de la guerra del 36 (Barcelona, Luis de Caralt, 1976, pp. 38-39, 214-216) volvería a refutar la idea de "la pretendida rebelión de los generales" porque "solo se unió al Alzamiento uno de los ocho jefes de Región Militar [...] y también solo uno de los tres generales de África [...]. Existían en la península 13082 jefes y oficiales, de ellos 5458 en zona roja [...] el total serian 7719 nacionales y 7624 rojos".

69 En La guerra de las dos Españas, op. cit., pp. 225-238, expresa con insistencia este concepto: "el apoyo extranjero favoreció más a los rojos que a los nacionales, prolongó la guerra, la enconó, y sólo puso en el balance final un mayor aniquilamiento" (p. 227). Por lo que se refiere a los moros, indica que se trataba de "fuerzas regulares del protectorado" y reitera que la "caballería mora" fue una leyenda. Como de costumbre, su objetivo se cifra en contradecir las palabras de los narradores "rojos": "el empleo de las fuerzas regulares indígenas en la guerra del 36 se convirtió en tema tópico de la literatura marxista" (p. 220). Entre estos autores, Malraux y el omnipresente Sender que "no veía por allí más que moros". Reduce también la presencia de las fuerzas nazis y fascistas con datos que probarían el mayor número de aviones en el bando republicano: "Los nacionales adquirieron un total de 1253 aviones extranjeros y los rojos 1360, de los cuales 1008 eran rusos”. La ayuda ítalo-alemana fue, así, una respuesta al "envío masivo de material" por parte de la URSS, que provocó, como reacción, el envío de "la Legión Cóndor y la Aviación Legionaria" (p. 238).

70 De aquí en adelante en las citas textuales se indica entre paréntesis el número de la página del correspondiente pasaje de E2. 
En el informe no falta un último reparo sobre el estilo "bajo", particular muy frecuente en la censura de novelas de la época. Gárate condena el lenguaje "que no perdona ninguna palabra del argot tabernario y de las tintas negras, exageradas hasta la caricatura”, sin percatarse de que lo verosímil en literatura impone un decoro a los personajes y a su expresión. Sin embargo, no indica ningún pasaje que haya que tachar por este motivo.

Por todas estas razones, reputa Manso "rigurosamente inaceptable". Juzga especialmente grave la novela, tanto que "parece afectada por el Código de Justicia Militar"; de ahí que solicitara un "informe previo del Estado Mayor Central del Ejército", invocando medidas que fueran más allá del nivel editorial. Para aceptar su salida comercial propone cambiar la ambientación: el antimilitarismo, la "ambición”, "la picardía”, la actitud "demoledora", la presencia de militares afeminados cuadran más en el "Ejército Rojo". Entonces, sin parar mientes en distorsionar por completo el sentido de la obra, y falto de escrúpulos a la hora de mantener la coherencia histórico- narrativa, plantea la posibilidad de modificar unas "veinte o treinta" líneas y situar la novela en Asturias, invirtiendo a su vez el papel de los bandos. La otra solución —quizá sugerida por otro funcionario- sería desplazar las peregrinaciones de Manso a un lugar lejano, como Cuba. Se quitaría así cada referencia a España y a la Guerra del '36. En un país y un ejército comunista serían perfectamente admisibles las atrocidades de los militares y sus mandos grotescos.

Afortunadamente para Lueiro y para los lectores no se llevó a término esa ardua y descabellada reescritura.

\subsection{La primera edición}

La Superioridad se inclinó por mutilar la obra sin impedir su publicación. Como ha explicado Larraz, era una decisión muy común y formaba parte de una estrategia para "favorecer la imagen liberal del estado", enmascarando así su cara más represiva ${ }^{71}$. Las denegaciones, en cambio,

71 Fernando Larraz, op. cit, p. 100. Cfr. también Ramón Buckley, La doble Transición. Politica y literatura en la España de los años setenta, Madrid, Siglo Veintiuno de España, 1996, pp. 3-10, quien afirma que hubo una cierta tolerancia del Régimen 
podrían proporcionar una involuntaria publicidad a autores hostiles a la dictadura.

En el AGA no hay otra documentación que permita explicar las causas de la resolución. De todas formas, el proceso fue rápido. El 17 de febrero, solo una semana después del informe de Gárate, la Administración mandó una carta a la editorial en la que ordenaba, con el habitual lenguaje eufemístico, expurgar algunos fragmentos: "se aconseja la supresión de los pasajes señalados en las páginas 81-84-86-87-89-107-114-120-131-132136-138-139-140-141-145-166-178-188-189-191-192-194-195-196199-214-224 del ejemplar original adjunto". Se indican entonces 28 pasajes: unas 80 líneas, que corresponden en total a dos páginas y media de $M$. La censura se reduce casi a una cuarta parte de lo que indicaba Gárate y acoge cuatro de las cinco indicaciones de HM (se admite solo el último pasaje, el de la h. 220). $M$ muestra este tercer nivel de intervención: un funcionario de la Superioridad con bolígrafo azul tachó los lugares definitivos que había que suprimir y los enmarcó dentro de los símbolos $<>$.

La editorial no interpuso recurso de reposición: una opción que la ley consentía, pero que sometía por segunda vez el libro a la arbitrariedad y el capricho de la oficina, sin ninguna garantía de una resolución menos invasiva $^{72}$. Primó, en cambio, la voluntad de publicar el libro cuanto antes. Parece que Lueiro no aceptó en un primer momento la publicación con estas condiciones. Se abrió así un contencioso que trascendió los departamentos ministeriales y el entorno de la editorial, y que por afectar a una novela galardonada llegó a los periódicos. El 21 de marzo La Vanguardia titulaba "Confusa situación en torno al Premio Ciudad de Oviedo de Novela":

hacia el "campo cultural" a partir de los Sesenta. Policía y censores vigilaban vidas y obras de los escritores, pero raramente llegaban a prohibir sus encuentros y sus libros. Para el crítico, la dictadura solo "se aseguraba de que aquella oposición [...] no pasara de ser puramente testimonial, de que nunca iba a pasar a la acción política". Para representar este simulacro de libertad y el destierro de escritores e intelectuales dentro de las páginas de los libros, Buckley acuña la definición de "cárcel de papel”.

72 El combativo editor Carlos Barral, Memorias, Barcelona, Península, 2001, p. 399, enumera los riesgos de solicitar una revisión: "primero porque las segundas lecturas eran mucho más lentas, como si el funcionario protestase contra la impertinente insistencia del editor, $y$, sobre todo, porque lo más frecuente es que el ejemplar regresase con nuevas y sorprendentes tachaduras, sustituyendo o no a las anteriores". 
Como consecuencia de ciertos párrafos de la novela Manso, [...] se ha creado una confusa situación entre el Ayuntamiento ovetense, la Junta de Censura, el editor de la obra y el propio autor de la misma. El Ayuntamiento de Oviedo envió dicha novela a la Junta de Censura porque estimaba que en ella había ciertos aspectos de matiz tendencioso en el campo político. La junta estimó procedente tal reclamación y acordó suprimir los párrafos pertinentes. Sin embargo, el autor de la novela, funcionario de Hacienda en Pontevedra, estima que en su obra no existe ningún punto dudoso en materia política y que no está dispuesto a permitir ninguna corrección. A tal fin, se asegura que Manuel Lueiro pretende devolver las 100.000 pesetas del premio y recuperar la obra para evitar que se publique retocada. Por su parte, el editor afirma que la novela será publicada en el próximo mes de abril, pero con las oportunas modificaciones. Tal disparidad de criterios parece indicar que, de no llegarse a un acuerdo amistoso el asunto pasará a los tribunales ordinarios, que decidirán sobre el particular ${ }^{73}$.

El diario manifiesta claramente su conformidad con el aparato estatal en el tratamiento de un tema tabú, como era la existencia del órgano de inspección editorial. Desaparece del todo su papel opresivo y se evita la palabra "censura", reemplazada con términos neutros como "corrección" y "modificaciones". La Vanguardia alude, además, a otra corporación que intervino en la polémica e interfirió en la publicación, el Ayuntamiento de Oviedo, al que contactó la "Junta de censura”. Esto podría significar que, por un lado, forzó a la editorial a elegir la "consulta voluntaria” y, por otro, ejerció presiones para podar el texto antes de solicitar la autorización, como avanzábamos en $\$ 4.1$.

Tres días después, en la citada entrevista concedida al Faro de Vigo, Lueiro aclaraba su opinión. Defendía la libertad de la literatura para incluir la cuestión de la guerra, y expresaba su amargura por lo ocurrido:

La Junta de Censura dispone, ordena y manda [...]. Entre el autor y el editor hubo siempre acuerdo. Pero intervino la Junta de Censura y se produjo este compás de espera [...]. Ignoro cómo funciona y

73 La Vanguardia, 21/3/1967, p. 11. 
el criterio que le guía. El editor coincide con el autor y el jurado. Ninguno ha visto en la novela motivos de "corte". [...] Hablar de la guerra civil no creo que sea pecado. Al jurado le pareció lo mismo y le concedió el premio [...]. La guerra civil es un hecho histórico. Los hechos históricos son novelables [...]. Deseo que estas situaciones no vuelvan a repetirse. Entiendo que nada hay peor para un pueblo que sujetar la muñeca del escritor.

A la pregunta de si la intervención censoria "mutila, efectivamente, el contenido de la obra", respondía el escritor: "Sustancialmente, no. Si fuese así habría que evitar la edición. De todas formas, todo "corte" produce desasosiego, es decir, crea una situación molesta”. Añadía también que las supresiones se traducen en el perjuicio "de ver un tanto "debilitado" lo que se hizo con una gran pasión creadora". Finalmente, confirmaba la intención de devolver el importe del premio, a condición de quedarse con todos los derechos, y concluía que en abril el libro estaría "en la calle". Lueiro se resolvió entonces a editar la obra mutilada, pensando ya, evidentemente, en publicarla íntegra fuera de España. Sin embargo, a pesar de tan optimistas previsiones, no pudo salir — por lo menos de manera legal — en abril. La disputa con el Servicio retrasó en varios meses la impresión, y solo el 3 de junio la editorial mandó a la Administración los ejemplares privados de los pasajes antedichos. Es el texto definitivo de E1. Además de los cortes impuestos, registramos algunas sustituciones y añadidos que la superioridad había indicado (con bolígrafo azul) en $M$ :

- Si no huye lo hubiesen fusitado > Si no huye lo hubiesen cogido (p. 187);

- Por las calles se veían soldados te las furerzas alemanas e italianas > Por las calles se veían también soldados (p. 194);

- El teniente López montaba con apostura afeetada y dirigía los movimientos $>$ El teniente López a caballo dirigía los movimientos (p. 195);

- Él me dice que en Marruecos y en Sevilla ya dominan los rebeldes > Él me dice que en Marruecos y en Sevilla hay tiros (p. 76).

Sobre esta última tachadura, en $M$ se había agregado, manuscrito, "Hay Alzamiento". En otro sucesivo pasaje del mecanografiado se daba el mis- 
mo fenómeno ("Alzamiento" en lugar de "los rebeldes", p. 87). Estas dos correcciones parecen de la misma mano que hizo las otras sustituciones. Sin embargo, por razones que ignoramos, no se aceptaron. Aun así, "rebeldes" se elimina de la edición: con una reformulación en el primer caso, y borrando del todo la frase en el segundo. "Rebeldes" fue un verdadero imperativo léxico de la censura, que intentó suprimir sistemáticamente la palabra en el contexto de toda la literatura de posguerra. De esta manera, se otorgaba más prestigio a la insurgencia, negando que fuera un golpe militar contra el legítimo gobierno de la República.

La Administración controló el nuevo texto y dio su visto bueno. El 8 de junio se estamparía el sello en el primer informe: "comprobadas y conforme las tachaduras". No obstante, el trámite todavía no había terminado: surgió, en fin, un pequeño problema burocrático. La editorial había mandado cuatro y no seis ejemplares, según contemplaba la ley. El 15 de junio Richard Grandío hizo llegar los otros dos, y el depósito se aceptaba cuatro días después. Solo entonces, casi cinco meses después de la solicitud, se cerraría el trámite. Ese mismo día, $A B C$ anunciaba la salida de Manso en su sección "Escaparate de librería ${ }^{74}$.

La tirada fue de cinco mil ejemplares ${ }^{75}$. Sin embargo, Alonso Montero informa de que el libro no permaneció demasiado en las estanterías porque "o Ministerio, instado polos militares ou por persoas de mentalidade militarista, ordenou que os exemplares desa edición fosen retirados das librerías" 76 .

La represión no se detuvo, sino que hubo secuelas. En otoño de 1968, con ocasión de la séptima entrega del "Premio novela ciudad de Oviedo", el Ayuntamiento asturiano puso veto a la participación en el jurado de los que habían premiado Manso: Ángel María de Lera, Alejandro Núñez Alonso y Ramón Solís. En un detallado artículo, la Revista SP refiere la cuestión, ratificando el papel del Ayuntamiento en la censura de Manso:

La novela premiada, "Manso", [...] fue calificada de comunista por el representante del Ayuntamiento que formaba parte del jurado, en sustitución del alcalde [...]. Al parecer, el Ayuntamiento centró un

$74 A B C, 15 / 6 / 1967$, p. 22.

75 Ramón Nicolás, "Introducción”, p. 102.

76 Alonso Montero, "Sobre Lueiro", p. 18. 
especial interés en eliminar del jurado al novelista Ángel María de Lera, según la opinión del Ateneo ${ }^{77}$.

Ángel María de Lera - excomandante republicano y por entonces reconocido novelista - fue quien apoyó la obra con más entusiasmo, pagando de esta manera su apuesta. En cambio, el responsable del veto debió de ser Anselmo López, que se enroló asimismo en el jurado. Por tanto, deducimos que ya en el propio certamen "el primer teniente de alcalde" se había opuesto a la victoria de Manso, y posiblemente fue él quien luego advirtió a las autoridades de la inclinación “comunista” de la obra. Ese año ganó el premio ovetense Domingo Manfredi Cano (que fue director de Radio Nacional de España en Sevilla) con la novela Los resentidos.

\subsection{La injerencia de los militares}

En virtud de los cortes efectuados por la Administración, vemos que no se interviene para castigar el lenguaje "realista" denunciado por Gárate, ni las escenas de la mísera situación de la Espańa de posguerra, dominada por una cínica oligarquía (el personaje de Ramírez), ni menos aún la latente sed de justicia social que anima al pueblo y de la que se hace portavoz Basilio. Se confirman así las palabras de Oskam, para quien, en general, "las prohibiciones se referían más bien [...] a la crítica al franquismo, mientras que se toleraba la crítica social en abstracto"78. Todos los

77 Revista SP, 422, 27/10/1968, pp. 25-26. Poco más de dos semanas después, en el diario $A B C(14 / 11 / 1968$, p. 49) se lee que la novelista Dolores Medio "ha enviado sendas cartas al presidente del Ateneo de Oviedo y al alcalde [...] renunciando al cargo de Jurado [...], por solidarizarse con sus compańeros vetados públicamente".

78 Jeroen Oskam, "Novela social y prensa crítica: revisión de una hipótesis", Anuario de estudios filológicos, XIV (1991), pp. 335-344 (p. 336). Cfr. también la conclusión de Francisco Álamo Felices, La novela social española. Conformación ideológica, teoría y crítica, Almería, Universidad de Almería, Servicio de Publicaciones, 1996, p. 93,: "los censores [...] en la denuncia social de las novelas social-realistas —obreros despedidos y explotados, situaciones de extrema injusticia, humillaciones de los que [...] habían perdido la guerra, emigraciones, muertes, incluso - únicamente vieron cuadros más o menos costumbristas", y por ello esta narrativa "pasó sin excesivos problemas, simplemente, ante lo censorio, sin que se observara un planteamiento 
pasajes censurados, entonces, están relacionados con uno de los cimientos de esa dictadura nacida con la victoria del 1 de abril de 1939: el ejército y la Guerra Civil. Los cortes apuntan a dinamitar el alcance reivindicativo de la novela, amortiguando los episodios de violencia, vejaciones y mezquindades del Ejército Nacional durante el conflicto, con el objeto de diluirlos en un cuadro más borroso.

La salvaguardia del honor del ejército enfrentado a los "rojos" fue una de las prioridades del departamento de censura. La ósmosis, por no decir identidad, entre los principios del Régimen y del ejército dio lugar a una fervorosa exaltación propagandística de las fuerzas armadas en todos los canales de comunicación, y al consiguiente control sobre todo lo que las afectaba ${ }^{79}$. De la misma manera, hubo una copiosa presencia de militares en todos los aparatos del Régimen. No hace falta insistir en el destacado papel que, aún en los años sesenta, el ejército desempeñaba dentro del Estado, ocupando cargos y funciones que iban mucho más allá de la seguridad nacional. Hasta el punto de que, como subraya Soto Carmona,

hubo una politización activa de ciertos mandos procedentes de las Fuerzas Armadas, que actuaron más como políticos que como militares [...]. Nadie podía competir con el Ejército, que mantenía un papel diferenciado del resto de las "familias". Y ese papel diferenciado fue una constante, sin posibilidad de vuelta atrás, mientras Franco estuvo presente ${ }^{80}$.

estético revolucionario". El mismo estudioso ha transcrito y analizado informes de novelas del mismo jaez en La censura franquista en la novela española de postguerra (análisis e informes), Granada, Investigación \& Crítica, Ideología Literaria en España, 2005.

79 Cfr. Manuel de Ramón Carrión, "La imagen de las fuerzas armadas en los medios de comunicación social durante el franquismo", en Los ejércitos del franquismo (1939-1975), coords. Fernando Puell de la Villa y Sonia Alda Mejías, Madrid, Instituto Universitario General Gutiérrez Mellado, 2010, pp. 517-544.

80 Álvaro Soto Carmona, "Militares en la política en la España Franquista", en Los ejércitos del franquismo, pp. 365-384 (p. 371). Cfr. también Joaquim Lleixà, Cien años de militarismo en España. Funciones estatales confiadas al Ejército en la Restauración y el franquismo, Barcelona, Anagrama, 1996, especialmente las pp. 143-168. 
Esto explica también la presencia de militares como Luis Martos, Fernández-Monzón y Gárate en el departamento de censura; y, a la vez, la absoluta necesidad de proteger al ejército de las palabras infamantes de la literatura "comunista".

\subsection{La reescritura de la Guerra}

A pesar de compartir la misma ideología, los altos funcionarios y Gárate muestran una diferencia de método evidente. Como decíamos, la superioridad lució un afán de intervención más mesurado con respecto al militar, que era partidario de la denegación o, por lo menos, de la supresión de amplios fragmentos. Señalaba, pues, bloques enteros, y en un caso llegaba incluso a cortar tres páginas y media seguidas (pp. 117-120): gran parte del diálogo entre Basilio y el sargento que requisa el caballo. Asimismo, pedía que se quitara la presentación de "Mariposa" la primera vez en que se le nombra, sin tener en cuenta que luego el lector se habría topado con un personaje desconocido.

Los cortes realizados, en cambio, son más "puntuales". A veces se elimina una sola palabra, la mayoría de las veces un adjetivo; como en este fragmento sobre el miedo instaurado por la guerra en los aldeanos: "A cualquiera de los vecinos podía llegarle de la noche para la mañana, la situación difícil y el peso duro del sacrificio inútil" (p. 107); o cuando el sargento pasa lista: "Las voces suenan en el patio como una letanía fúne= bre" (p. 165). En otras ocasiones, se elide un inciso o una especificación, como si no se quisiese cercenar del todo la acción que se está describiendo, sino limpiarla de su acento negativo. Así se neutraliza, por ejemplo, la reacción de los viajeros cuando contemplan a los militares: "La poca gente que tenía necesidad de viajar miraba eon gesto hoseo el movimiento de las operaciones" (p. 132).

En contadas oportunidades, empero, se tachan partes más amplias. La más extensa la constituyen las 26 líneas del diálogo entre Servando y Basilio acerca de la muerte de José (pp. 190-191), que incluye las acusaciones contra los militares. Aquí la superioridad decidió no intervenir con el bisturí, sino borrar de un plumazo toda la secuencia. 
Tras cotejar los cortes indicados por Gárate con el resultado definitivo, nos damos cuenta de que no solo se salvan muchos pasajes que el teniente coronel juzgaba inadmisibles, sino que, incluso, en cinco ocasiones se eliminan otros que el censor no había señalado. El más relevante alcanza las cinco líneas; se trata, de nuevo, de un ataque de Basilio contra los militares (p. 84). Los otros casos afectan a pocas palabras, verbigracia: “el teniente López era un militar que en ningún momento estaba dispuesto a realizar un acto de heroísmo" (p. 177). La tachadura acusa la obsesión por no mellar las prendas del ejército; no cambia, pues, el sentido de la frase, pero se le otorga valor individual a la infamante afirmación, desvinculando a López de las fuerzas armadas.

El resto de las supresiones fueron sugeridas por los lectores y nacen de la preocupación por pulir cada sombra en el proceder del ejército.

En primer lugar, se procura despojar al texto de la atmósfera agobiante que envuelve a los jóvenes que lucharon en el frente nacional: "Ea tristeza es el gesto de todos" (p. 145); "Tú, al fin, [...] eres español, y vienes a la fuerza a laguerra" ( $p$ 197). Otro aspecto que se diluye es el autoritarismo de los mandos: "el sargento, con el rostro aún lleno de ira, dio dos golpes de fusta en la eabeza del soldado de La Coruña” (p. 137). Se supone así que para el lector que leía Manso en 1967, el sargento dio los golpes al aire, y de ahí la tachadura un par de líneas después: el "soldado agredido", consecuencia lógica de que no se ha producido ninguna agresión. De la misma manera se tachan las 17 líneas (pp. 137-138) en las que un soldado recuerda los abusos de este sargento y el postrer plan de venganza.

Se suprimen también las descripciones de la represión de los nacionales en las zonas "conquistadas" (cuando Basilio, refiriéndose a José, decía: "Eo fusilarían", p. 188) y se "suavizan" sus torturas: se mantiene que las hermanas de José "lo pasaron muy mal", pero sin pormenores: "Ees cortaron el pelo, le dieron aceite de ricino, y las tuvieron en la cáreel varios meses" (p. 187).

La contribución de las milicias extranjeras al lado del ejército se reduce de manera calculada. Las tropas marroquíes que lucharon en el campo franquista se borran del todo (" $y$ que los moros están pasando para Espa= ña, porque están unidos a los rebeldes", p. 76, y "los rebeldes contaban eon el apoyo de los moros, y los traían de Áfriea para haeer la guerra de España”, p. 87). Disminuye asimismo la importancia de las fuerzas 
alemanas e italianas, motivo al que Gárate volvía una y otra vez: "Los aviones de bombardeo en mano de alemanes vuelan en formación de tres" (p. 217).

Finalmente, desaparecen los insultos a los mandos castrenses (“ $¡ E s t e$ tío es un cabron!” > “¿Este tío!”, p. 137) y varios segmentos que los ridiculizaban. Así, cuando se pone de manifiesto la desproporción entre las ostentosas ambiciones de los superiores y la mísera realidad de la guerra: "y dio un ¡Viva Navarra!, eomo si después de una gran maniobra militar ta hubiese conquistado con la fuerza" (p. 194). Sobre todo, el Servicio no puede admitir las descripciones "denigrantes" y tampoco las mofas de los sargentos:

- se atusa el delgado bigotillo eon un gesto muy propio de ruffán deprostíbulo" (p. 114);

- Bendaña le llamaba "Mariposa" al sargento Laureano porque era rubio de cabello, un rubio plateado y sonrosado de cara, ytenf́a et andar afeminado, moviendo las caderas y los hombros como una mujer remilgosa (p. 199).

Se suprimen, por tanto, dos guiños tabú en la sociedad tradicional y católica de la posguerra (y, por consiguiente, de la censura), como son los burdeles y la homosexualidad, más si cabe cuando aluden a los soldados.

En conclusión, el objetivo del Servicio, a través de sus metódicas tachaduras, no era sino reescribir la historia de la guerra. No hubo "rebeldes" contra un gobierno legítimo, ni participaron los moros o bombardearon los aviones alemanes; los sublevados no fusilaban a los enemigos, ni mucho menos los altos mandos se atrevían a castigar a sus soldados.

Fue Antonio Tovar quien, desde Argentina, quizá por primera vez, pudo enfocar con total libertad esta clave de la novela de Lueiro, es decir, la intolerancia del Régimen hacia una lectura disconforme de la guerra. En su reseńa sobre Manso, el poeta recalcaba la dificultad en España para escribir narrativa sobre el conflicto, "con las trabas que, como es lógico, toda política defensiva opone a los peligros sociales que pudieran deri-

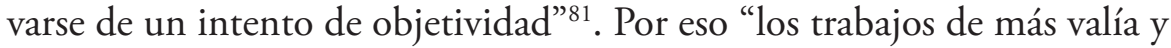

81 Antonio Tovar, "Sobre Manso, de Manuel Lueiro Rey", El Correo de Galicia: órgano de la colectividad gallega en la República Argentina, 29/2/1968. 
objetividad" habían salido de la pluma de desterrados: Salvador de Madariaga y Antonio Ramos Oliveira entre los historiadores, Barea y Sender en el campo de la narrativa. Lueiro, al igual que Gironella, representaría una admirable excepción en España.

Sin embargo, todavía no había acabado la batalla para restablecer la "verdad" y desterrar una novela subversiva que propugnaba una lectura sediciosa de la historia. Aunque las palabras de Tovar aparecieran en una revista de América del Sur, no iban a quedar indemnes. Así, la respuesta no se hizo esperar en España. Pocos meses después, en mayo, apareció una reseña en la publicación del Apostolado Castrense Reconquista, con el claro propósito de descalificar el elogio de Tovar. La firmaba José María Gárate Córdoba ${ }^{82}$. El teniente coronel vuelve a atacar la novela, ahora en el espacio público de una revista y no en los secretos informes del Servicio. Su tono, sin embargo, no cambia. Por el contrario, se nos antoja incluso más tajante: "Es "Manso" una novela magistral, como se ha atrevido a decir de ella Antonio Tovar [...]?”. Su respuesta es negativa; la clasifica de ingenua, irreal y de "malogrado tinte poético". En las dos páginas de la reseña repite, además, las mismas pullas del informe, cargadas de resentimiento, quizá fruto de ver editada una obra que deseaba prohibir. A la vez, expresa su aflicción por la pérdida de los valores del pasado y de la terminología sobre el conflicto que forjó el franquismo: "[la novela] no es tan mansa, pues no deja de soltar sus coces y relinchos, cosa obligada ahora en todo lo que se refiera a la llamada Guerra de Liberación y que de pronto pasó a llamarse Guerra Civil". En este sentido, lamenta sin ambages que se le haya otorgado el premio ovetense: "inexplicablemente, acaso por no haber nada más sensacional en el concurso". Un veredicto que considera una "paradoja", por fallarlo el "Excelentísimo Ayuntamiento" de la "heroica" ciudad asturiana, "salvada" durante la Guerra precisamente por una columna de gallegos "de las que antes se llamaron [columnas] heroicas". Vuelve a subrayar su repulsa hacia el retrato del Sargento Mariposa ("con su contoneo feminoide"), el Sargento López y el lenguaje vulgar: "concesiones a la literatura barata al cargar los lugares comunes, tabernarios o las expresiones rencorosas". No faltan las menciones, con palabras casi idénticas a las del informe, a Sender y Remarque (a los que

82 José María Gárate Córdoba, “Manso”, Reconquista, XIX, 221 (1968), pp. 50-52. 
añade ahora a Rousseau) como modelos negativos ("insiste abundantemente en los tópicos sensibleros, a lo Remarque", "Hay cierta tendencia a cuajar en un estilo mitad bucólico-realista, con influencias de Rousseau y de Sénder [sic]"). Se atreve también con explícitos juicios literarios llenos de sarcasmo: "Por ser novel puede perdonársele literariamente que recargue inoportunamente las tintas sombrías contra los soldados de Franco y sobre la zona nacional". Finalmente, repite que el autor habría tenido que ambientar la trama en el otro bando, y atribuye su elección tanto a motivos comerciales como al gusto por la polémica: “Todo valdría mejor en zona roja y la novela sería más verista. Pero acierta haciéndolo así en cuanto al escándalo, la taquilla y la labor de zapa”.

\section{LA SEGUNDA EDICIÓN}

La única solución para imprimir la novela íntegra era hacerlo en el exterior, fuera de la influencia directa del régimen culpable de la máquina de vigilancia y represión que se dejó sentir sobre E1. Lueiro intentó publicarla antes en París, donde trabó contacto con exiliados en la órbita del PCE gracias a su actividad militante ${ }^{83}$. Sin embargo, el proyecto no despegó. La segunda opción era Argentina, país que — como vimos_ - visitó a finales de 1968. Además de Manso, Lueiro tuvo la oportunidad de dar a la imprenta la colección Vicente y el otro, que contenía algunos cuentos sobre la Guerra Civil que, sin duda, la censura espańola habría prohibido o mutilado. En efecto, la capital federal argentina fue uno de los principales centros de edición de novelas proscritas o censuradas ${ }^{84}$. Allí, además, Lueiro se acercó a los múltiples proyectos editoriales puestos en marcha por los refugiados españoles ${ }^{85}$. Entre estos, la editorial y distribuidora Oberón, que se hizo

83 Xesús Alonso Montero, "Sobre Lueiro", p. 18.

84 Recordemos, por ejemplo, las primeras ediciones de La colmena de Cela (1951), Fiestas de Juan Goytisolo (1958), Sin camino de José Luis Castillo Puche (1956) o A esmorga (1959) de Eduardo Blanco.

85 Los ya citados Arturo Cuadrado, Luis Seoane y Lorenzo Varela fueron el principal nexo de conexión entre Lueiro y el universo hispanoamericano. Los tres protagonizaron numerosas iniciativas con el objetivo de conectar la cultura de la emigración gallega con la autóctona y su nueva realidad del exilio. Sobre el tema cfr. Xosé Luis Axeitos Agrelo, "Cultura y comunicación en el exilio gallego de Buenos Aires", en 
cargo de publicar ambos libros. Oberón nacía en el mismo corazón del exilio republicano, fundada por el militar y conocido militante del PCE Francisco Galán, en alianza con su mujer ${ }^{86}$. El 25 de octubre de 1968 se remataría la segunda edición de Manso y la primera — y única- de Vicente y el otro ${ }^{87}$. El amigo Luis Seoane dibujó las portadas. Francisco Lores ${ }^{88}$

La cultura del exilio republicano español de 1939. Actas del Congreso internacional celebrado en el marco del Congreso plural: Sesenta años después (Madrid-Alcalá-Toledo, diciembre de 1999), coords. Manuel Llusia y Alicia Alted Vigil, Madrid, UNED, 2003, 1, pp. 117-128; y Luis Seonae e o libro galego na Arxentina (1937-1979), coords. Xosé Luís Axeitos y Xavier Seoane, A Coruña, Diputación, 1994, pp. 6-25. 86 Francisco Galán (1902-1971) fue coronel republicano y uno de los jefes del Quinto Regimiento. Durante la Guerra luchó en la defensa de Madrid y fue al mando del Ejército Rojo en la batalla de Teruel y en las campañas en Asturias y Cataluña. Vivió el exilio en Chile, Argentina y Uruguay. Además de Oberón, creó otro sello editorial, Periplo. Sobre su vida, cfr. Victoria Fernández Díaz, El exilio de los marinos republicanos, Valencia, Publicacions de la Universitat de València, 2009, pp. 155156, mientras que acerca de las editoriales véase María Teresa Pochat, "Editores y editoriales", en El Destierro español en América: un trasvase cultural, comp. Nicolás Sánchez-Albornoz, Madrid, ICI, Sociedad Estatal Quinto Centenario, 1991, pp. 163-176; y, en el mismo volumen, Epifanio Madrid Díez, "La distribución del libro como instrumento de difusión cultural" (pp. 177-181) quien subraya "la labor de Francisco Galán con su distribuidora" (p. 179).

87 El rastreo en los catálogos confirma que la editorial estuvo activa en los años cincuenta y sesenta. Imprimió en primer lugar obras de autores antifranquistas, textos sobre la Guerra Civil o literatura prohibida en España, como: Culminación y crisis del imperialismo (1954) del jefe del Estado Mayor del Ejército Republicano Vicente Rojo, o No me avergoncé del Evangelio (desde mi parroquia) (1958) del sacerdote Marino Ayerra Redin. Editó también libros de argentinos que participaron en el conflicto, como Añoranzas bélicas (1966) de Rafael María Zúñiga y Los que no perdieron la Guerra (1967) de Víctor de Frutos (que en el frente norte estuvo al lado de Francisco Galán), o los relatos La saca del comisario político Luis Alberto Quesada (1963). Hay que citar también la segunda edición en español de El fin de la esperanza. Testimonio (1956), atribuido a un tal Juan Hermanos (en realidad obra del joven izquierdista Marcel Saporta), crónica desde dentro de la lucha clandestina en la primera posguerra. No faltan en el catálogo títulos poéticos (por ejemplo $\mathrm{Pa}$ norama de la poesía moderna de Enrique Azcoaga, 1953), de historia (dentro de la única colección de la editorial, la Serie Histórica de Investigación y Crítica, dirigida por Enrique de Gandía) o ensayos de temas considerados tabús, como el de Peter Wildeblood, Contra la ley (El homosexualismo en Inglaterra), que data de 1962.

88 Francisco Lores, op. cit., pp. 9-10. 
recuerda que la "Unión Hijos del Grove" quiso financiar por entero los dos libros, pero la falta de fondos lo imposibilitó. La asociación ofreció igualmente apoyo económico, como confirma el idéntico colofón: "Auspiciado por Unión Hijos de El Grove”. En ambos colofones se lee también que los volúmenes fueron "cuidados" por Arturo Cuadrado. Pocos días después, el escritor tendría la oportunidad de presentar estas publicaciones en el auditorio de la Galería Kraft de Buenos Aires. Ramón Nicolás afirma que la tirada de la segunda edición fue muy amplia (diez mil ejemplares). No obstante, se agotó enseguida, difundiéndose seguramente en los círculos de los refugiados ${ }^{89}$. En España, en cambio, gozó de una circulación limitada, si no nula. Entró solo de manera clandestina, ya que no habría tenido esperanzas el intento de importarla de manera legal. No en balde, tuvo tan escaso eco que no hemos podido localizar nuevas reseñas. La negación de la existencia de la censura impedía, por supuesto, que se pudiese hablar explícitamente en medios oficiales de una novela remendada por el Servicio de Orientación Bibliográfica y editada íntegra en el exterior.

\subsection{Cuestiones textuales}

E2, según decíamos, presenta un texto mucho más extenso que $E 1$, habida cuenta de que restablece los pasajes censurados por la Administración estatal. Sin embargo, incluye también muchos fragmentos que faltaban ya en $M$ (cfr. $\$ 4.1)$. Se trata de secuencias enteras y, también, de detalles descriptivos, como por ejemplo:

En las caras de los soldados se refleja el cansancio, y todos ellos levantan las piernas con esfuerzo, cediendo terreno $(M)>$ En las caras de los soldados, llenas de sudor y polvo, se refleja el cansancio, y todos ellos levantan las piernas con mucho esfuerzo, cediendo terreno y velocidad a la marcha (E2, p. 145).

Otro caso es ejemplar de las modificaciones de la misma frase en las tres redacciones:

89 Ramón Nicolás, "Introducción”, p. 102. 
$M$ : "defendiendo al gobierno, fieles al juramento de la bandera"; E1: "defendiendo al gobierno";

E2: "defendiendo al gobierno de la República, porque continuaban siendo fieles al juramento de la bandera” (p. 87).

Solo en la tercera Lueiro pudo, por fin, expresarse libremente. Un último ejemplo de leve amplificatio en E2 da cuenta de cómo en $M$ se edulcoraba la tragedia de la guerra: "comienza la evacuación de los heridos" $(M / E 1)>$ “comienza la evacuación de los heridos y muertos” (E2, p. 217).

El cotejo entre el mecanografiado y E2 alumbra otros pormenores de fuste. Además de los añadidos, E2 muestra las marcas del tortuoso camino que atravesó Manso, y también una cierta prisa en su impresión, seguramente fruto de las circunstancias y del poco tiempo que Lueiro permaneció en Argentina. Se advierte alguna lección errónea de E2 frente a la correcta de $M$ (y E1), secuela de simples descuidos, como "arrastrando" > "arrantrando" (p. 14); "mulos" > "nulos" (p. 156); "practicante" > "prácticamente" (p. 197). Tampoco se enmienda un error de $M$ ("nerviosos" en lugar del correcto "nervios", p. 182) que sí se había corregido en E1. Aparecen asimismo algunas variantes (poco más de veinte en total, excluyendo los ańadidos) que no alteran demasiado el contenido semántico. Por ejemplo, de $M$ a E2: "hierve" > "sigue hirviendo" (p. 77); "armas" > "fusiles" (p. 84); "escalofrío por todo el cuerpo" > "escalofrío que lo dejó paralizado" (p. 90), "abriendo el canalillo"> "cubriendo el canalillo" (p. 189), "llamándole, llamándole, llamándole" > "llamándole" (p. 208). Podrían ser correcciones que Lueiro (o Cuadrado) hizo en esta fase, en vísperas de imprimir la segunda edición. Suponemos que obedecen a variantes de autor también algunas pequeñas reescrituras (pero no sabemos si estaban ya en $O$, por el contrario son resultado de una reelaboración). Por ejemplo: "clavetea el cuero. Antes fijó la pala con dos puntas, una clavada en la parte del talón y la otra en la puntera" > "clavetea la parte del talón y la otra en la puntera” (p. 189).

Más sorprendente que en contadas ocasiones falten partes que figuraban en $M$ y que fueron expurgadas en $E 1$ por la oficina estatal. E2 reproduce, entonces, el mismo texto censurado. Así de $M$ a E1/E2:

- el peso duro del sacrificio inútil > El peso duro del sacrificio (p. 107); 
- que también se llevaban los hombres y nadie protestaba > que también se llevaban los hombres (p. 130);

- La poca gente que tenía necesidad de viajar miraba con gesto hosco el movimiento de las operaciones. Nadie hacía comentarios. Sabían todos que el hacerlo suponía correr un riesgo > La poca gente que tenía necesidad de viajar miraba el movimiento de las operaciones. Nadie hacía comentarios (p. 132).

Hay que descartar que estas ausencias se deban a la voluntad de Oberón. Tampoco hay razón para afirmar que fuera el mismo Lueiro quien decidió sacrificarlas. Sin embargo, no puede ser casual que falten precisamente varios segmentos censurados. De nuevo, no contamos con datos para dar una respuesta segura. Se podría conjeturar que, en algún momento, por el taller de Oberón circuló el mecanografiado remitido por el Ministerio, una copia con anotaciones de las censuras o el mismo E1, y, en la tarea de devolver el texto a su origen, se olvidaron tales segmentos.

Finalmente, hay que señalar que una corrección manuscrita en $M$ (hecha probablemente por alguien implicado en la copia, si no por el mismo mecanógrafo) no se ha respetado ni en E1 ni en E2. Es una errata evidente: “¿A ti, Servando?” (p. 96). En $M$ se enmendó escribiendo encima "Basilio", ya que es el mismo Servando quien pronuncia la pregunta y se dirige al amigo. Este descuido tampoco se ha subsanado en la traducción gallega (p. 113).

En definitiva, el análisis de toda la documentación de la que disponemos y el cotejo entre las tres versiones nos hace creer que para preparar E2 se utilizó $E 1$ o un mecanografiado censurado, y que luego el autor añadió sus interpolaciones en el intento de devolver la novela a una fase anterior a $M$, es decir, previa a todo tipo de censura y autocensura. Las erratas, descuidos y los residuos de la censura presentes en E2 manifiestan, a la vez, la necesidad de acometer una edición crítica de Manso. En esta tarea hay que plantearse un problema clave para la fijación textual, que se resume en dos opciones: 1) la reconstrucción del texto ideal, introduciendo entonces también las omisiones que $E 1$ transmitió a $E 2 ; 2)$ no alterar $E 2$, ya que no podemos demostrar que tales expurgos se debieron a un descuido, sino que tal vez respondieran a la última voluntad del autor. 


\section{Conclusiones}

La represión sufrida por Lueiro ha demostrado, una vez más, cómo la dictadura franquista condicionó todas las facetas de la producción editorial. Sus tentáculos se extendieron hasta los certámenes literarios, imponiendo los miembros del jurado y sesgando sus veredictos; llegaron a manipular a la prensa y sometieron a los escritores a interrogatorios y registros. El Servicio de Orientación Bibliográfica emanó de este sistema totalitario, a fin de vigilar la ortodoxia de las palabras impresas en España. Un departamento que Barral radicaba en las "cochambrosas dependencias de la planta baja del ministerio" 90 y que determinó cortes, sustituciones y prohibiciones, retrasó la edición de libros y retiró tiradas enteras. Finalmente, fue el responsable de que Manso, ganadora del premio "Ciudad de Oviedo", saliese mutilada.

En esta novela cabe hablar de una estratificación de la censura. En primer lugar, la misma existencia de ese control estatal ejerció una presión antes de que el mecanografiado transitase por las oficinas del Servicio, aplicando a escritor y editor una forma de autocensura. A esta se sumaría la represión oficial, encarnada en los bolígrafos de los censores y de la superioridad.

Los documentos del expediente de Manso permiten ahondar en las circunstancias que rodearon a la primera edición. Entramos así dentro de un organismo arbitrario en el que hallaban asiento posiciones que iban desde el radicalismo de Gárate a posturas un punto más “tolerantes” de otros funcionarios. El destino de la novela se fraguó entonces por el choque, o la mediación, entre distintas presiones, imponiéndose, finalmente, la decisión "pragmática” de autorizar la obra con un reducido número de cortes. De los informes destacan las figuras del par de censores. Del primero conocemos apenas su sigla: HM, un lector que se diría especializado en la obra de Lueiro o en las letras gallegas, puesto que de los nueve títulos del escritor grovense que pasaron por la Administración entre los Sesenta y Setenta, él juzgó cinco, independientemente de que se tratase de poesía o narrativa, en gallego o en español. Podríamos calificarlo como "moderado", porque sus propuestas apuestan siempre por la aprobación, aunque levanta sospechas sobre versos o párrafos políticamente inaceptables y, después de la Ley Fraga, se duele de la imposibilidad de recortar

90 Carlos Barral, op. cit., p. 454. 
partes. HM se muestra consciente de su papel subalterno dentro del departamento por su condición de simple (y casi nunca "definitivo") lector: en tres ocasiones, pues, apela a un "mejor criterio de la Superioridad".

Gárate Córdoba fue, en cambio, el más fanático enemigo de la novela y responsable de la mayoría de sus podas. El teniente coronel y Lueiro pueden considerarse como prototipos de las dos Españas que se enfrentaron en el 36 y que siguieron pugnando, con armas y en posiciones de fuerza más que distintas, durante el franquismo. Eran casi coetáneos, pero sus ideas, elecciones, recuerdos y pareceres los hizo luchar siempre en bandos contrapuestos. Sin embargo, sus destinos se cruzaron solo en 1966, en la Oficina de Censura. Por un lado, una novela contra la guerra, escrita por un poeta comunista que sufrió en su piel y en sus páginas las garras de la represión; por otro, un reconocido militar e historiador, parte del engranaje de una dictadura monocolor que no admitía posiciones no alineadas a este respecto, fue convencido de cumplir en el Servicio una misión para el Movimiento y de que aplicar cortes a una novela "roja” representaba una prosecución de los fines de la "Guerra de Liberación”. Se le ajustan, pues, como un guante estas palabras de Gubern: "la lucha armada encontraba su natural complemento en la lucha ideológica ejercida por la censura, es decir, en el control y represión de la producción y difusión ideológica que pudiera ser perjudicial a los fines perseguidos por el nuevo Estado”.

Las supresiones obligaron Lueiro a editar la novela en Argentina al año siguiente, a la par que muchos otros escritores que vivían en la patria sometidos a un "exilio interno". Así los lectores hemos llegado a disfrutar de la obra en su totalidad. Sin embargo, la edición bonaerense muestra un elevado número de variantes y no discurre falta de lapsus, erratas $\mathrm{u}$ olvidos. El caso de Manso confirma, por tanto, que el original de archivo es necesario para arrojar luz sobre las primeras fases del texto, y también para pulirlo de los residuos de la censura y de su complicada restauración. Solo el cotejo del material conservado, entonces, permitiría alumbrar la primera edición crítica de Manso y rescatar una novela emblemática de los riesgos y la represión que en época franquista sufrió la narrativa que se atrevía a atacar los cimientos ideológicos e históricos del Régimen. Finalmente, sería un debido homenaje a un autor que se sublevó contra las "verdades" impuestas por la dictadura, sin miedo a remover las peligrosas cenizas de la Guerra Civil. 